ARTICLE

\title{
Droplet printing reveals the importance of micron-scale structure for bacterial ecology
}

\author{
Ravinash Krishna Kumar (1) 1, Thomas A. Meiller-Legrand 2,3, Alessandro Alcinesio (1) 1, Diego Gonzalez ${ }^{3,5}$, \\ Despoina A. I. Mavridou4, Oliver J. Meacock (1) 2,3,6, William P. J. Smith (1D) 2,3, Linna Zhou', Wook Kim (1D) 3,7, \\ Gökçe Su Pulcu', Hagan Bayley (i] ${ }^{1 凶}$ \& Kevin R. Foster (iD ${ }^{2,3 凶}$
}

\begin{abstract}
Bacteria often live in diverse communities where the spatial arrangement of strains and species is considered critical for their ecology. However, a test of this hypothesis requires manipulation at the fine scales at which spatial structure naturally occurs. Here we develop a droplet-based printing method to arrange bacterial genotypes across a sub-millimetre array. We print strains of the gut bacterium Escherichia coli that naturally compete with one another using protein toxins. Our experiments reveal that toxin-producing strains largely eliminate susceptible non-producers when genotypes are well-mixed. However, printing strains sideby-side creates an ecological refuge where susceptible strains can persist in large numbers. Moving to competitions between toxin producers reveals that spatial structure can make the difference between one strain winning and mutual destruction. Finally, we print different potential barriers between competing strains to understand how ecological refuges form, which shows that cells closest to a toxin producer mop up the toxin and protect their clonemates. Our work provides a method to generate customised bacterial communities with defined spatial distributions, and reveals that micron-scale changes in these distributions can drive major shifts in ecology.
\end{abstract}

\footnotetext{
${ }^{1}$ Department of Chemistry, University of Oxford, Oxford, UK. ${ }^{2}$ Department of Biochemistry, University of Oxford, Oxford, UK. ${ }^{3}$ Department of Zoology, University of Oxford, Oxford, UK. ${ }^{4}$ Department of Molecular Biosciences, University of Texas at Austin, Austin, TX, USA. ${ }^{5}$ Present address: Laboratoire de Microbiologie, Institut de Biologie, Université de Neuchâtel, Neuchâtel, Switzerland. ${ }^{6}$ Present address: Department of Physics and Astronomy, University of Sheffield, Sheffield, UK. ${ }^{7}$ Present address: Department of Biological Sciences, Bayer School of Natural \& Environmental Sciences, Duquesne University, Pittsburgh, PA, USA. ${ }^{凶}$ email: hagan.bayley@chem.ox.ac.uk; kevin.foster@zoo.ox.ac.uk
} 
B acteria commonly exert strong effects on the growth and survival of surrounding cells via mechanisms that include nutrient competition, quorum sensing and toxin production $^{1-4}$. Consequently, the position of different strains and species in space is thought to be critical for the ecology of bacterial communities, and indeed how they affect us ${ }^{5-11}$. In particular, the way in which different strains of bacteria are arranged when a community first develops is expected to be a key predictor of which strains dominate and, more generally, whether the community thrives or perishes ${ }^{12-21}$. When strains and species grow apart in distinct patches, for example, this is expected to limit the impacts of competitive mechanisms, thereby promoting both coexistence and productivity.
The importance of spatial structure is broadly supported by comparisons of liquid with solid-surface (agar) culture, and agarbased manipulations on the millimetre-to-centimetre scale (Fig. 1b $)^{22-27}$. However, natural spatial structure often occurs at much finer scales, with data from the mammalian microbiome suggesting that the micron-to-millimetre scale is particularly important $t^{6,11,28}$. For example, while there appears to be significant genotypic mixing in the gut microbiome ${ }^{29}$, the dental and tongue microbiome is more structured, with patches of bacteria dominated by one genotype reaching tens to hundreds of microns in scale $8,9,30$. Moreover, there is evidence that solute gradients within bacterial communities can limit the distance at which cells affect each other to micron scales ${ }^{31-33}$, raising the possibility that
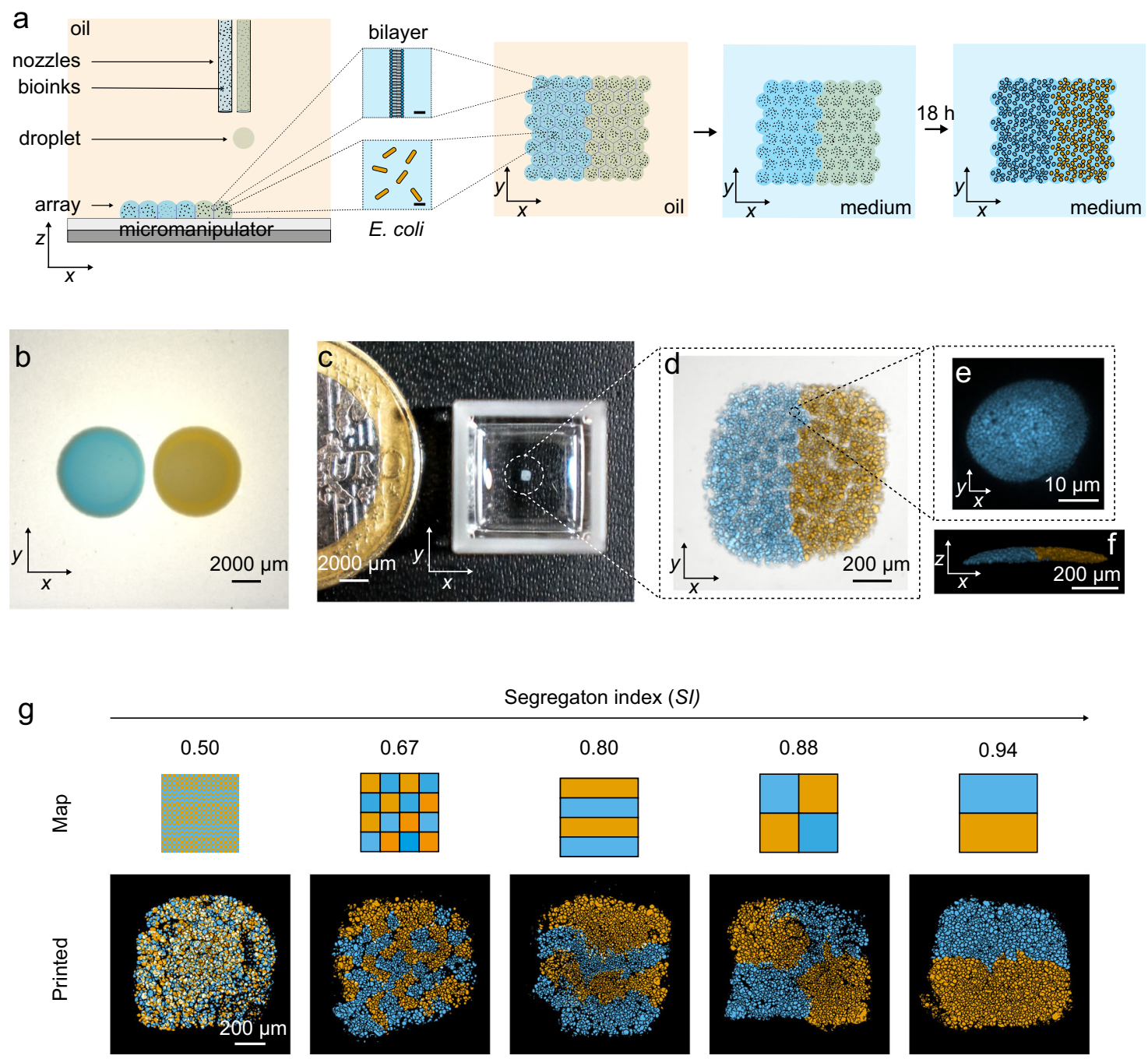

Segregaton index (SI)
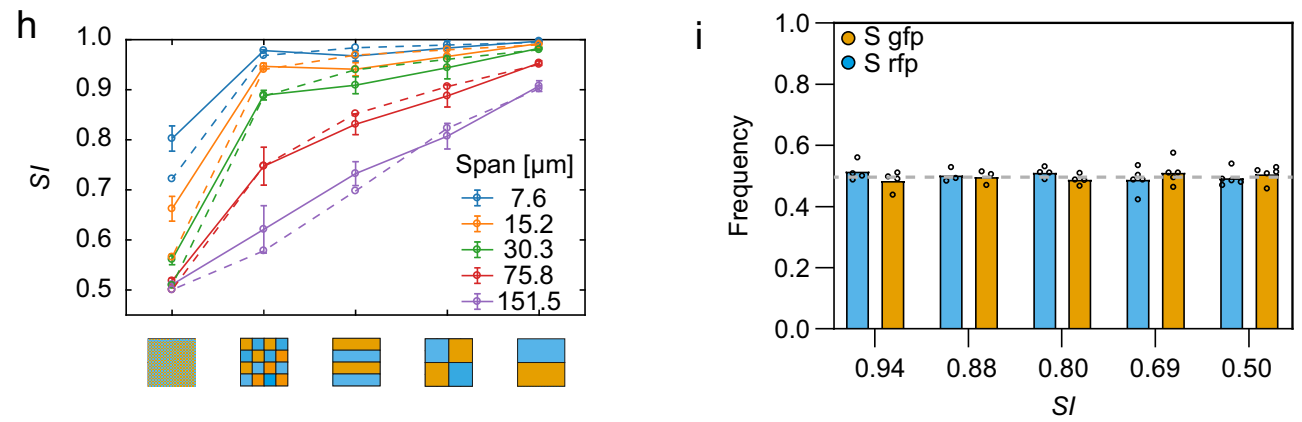
Fig. 1 Droplet printing generates viable bacterial communities with defined micron-scale patterning. a A schematic of the fabrication of printed bacterial communities by droplet printing (depicted in the $x, z$ and $x, y$ dimensions), transfer to LB medium and growth. $\mathbf{b}$ A composite (brightfield and fluorescence) stereomicroscope image of two side-by-side spotted colonies of susceptible (S) gfp and S rfp strains grown for $24 \mathrm{~h}$ at $37^{\circ} \mathrm{C}$ from starting cell densities of $10^{8}$ cells mL $\mathrm{mL}^{-1}$. c A photograph of a printed array (after $18 \mathrm{~h}$ of growth and transfer to $\mathrm{M} 9$ medium) with a 1-euro coin for size comparison. Images in $\mathbf{b}$ and $\mathbf{c}$ are taken at the same magnification. $\mathbf{d}$ A higher magnification, composite (transmitted light and fluorescence) confocal microscope image of a $7 \times 8 \times 1(x, y, z$ droplets) printed array containing S gfp and S rfp strains segregated to opposite sides of the structure. e A confocal fluorescence microscopy image of an $\mathrm{S} r \mathrm{fp}$ microcolony in the $x, y$ planes ( $n=4$ biologically independent experiments). $\mathrm{f} A 3 \mathrm{D}$ rendering of $z$-stacked confocal microscopy images of the same printed community as in $\mathbf{d}(n=4$ biologically independent experiments). $\mathbf{g}$ Segmented fluorescence images of printed communities $(7 \times 8 \times 1(x, y, z$ droplets $))$ of $S$ gfp and $S$ rfp strains at graded degrees of genetic mixing accompanied by the corresponding printing map and the calculated segregation indices $(S I)$ at a local neighbourhood of $100 \mu \mathrm{m}$ (see 'Methods'). The local neighbourhood is the spatial scale on which genetic mixing is measured. In $\mathbf{b}-\mathbf{g}$, $\mathbf{S}$ gfp and $\mathbf{S}$ rfp strains are false-coloured orange and sky blue, respectively. $\mathbf{h}$ A plot showing the calculated SI of printed arrays (smooth lines) at different sizes of local neighbourhoods ('spans') (7.6-151.5 $\mu \mathrm{m}$ ) compared to the $S /$ of the printing maps (dashed lines). Data points are the mean of $n=9$ printed arrays, and error bars are the standard deviation. $\mathbf{i}$ A bar chart showing the frequency of $\mathrm{S}$ gfp and $\mathrm{S}$ rfp strains in arrays printed at different $S /$ values. Each data point is a biologically independent replicate and the height of the bars are the mean frequencies of the strains. The grey line shows the initial starting frequency ( 0.5 for both genotypes). A Kruskal-Wallis test found a non-significant difference between the median frequencies of $S$ gfp at different $S I$ values ( $P=0.2736$; see Supplementary Table 1 for statistical tests). In $\mathbf{i}$, the term 'frequency' ( $f$ ) of a genotype $a$ in a printed array containing genotypes $a$ and $b$ after $18 \mathrm{~h}$ of competition is defined as $f=A_{a} /\left(A_{a}+A_{b}\right)$, where $A$ is the total cross-sectional area that a genotype occupies in the printed array.

differences in the arrangement of genotypes at these scales will have impacts.

While fine-scale spatial structure is hypothesised to be important for the form and function of microbial communities, direct tests are needed. A key barrier is a requirement for a technology that can manipulate the patterning of interacting bacteria at the relevant spatial scales. A range of printing technologies exists to position and pattern microbes ${ }^{34-39}$. However, the typical focus of this work has been the production of biomaterials, such as bacterial sensors (e.g., bacteria embedded in a $3 \mathrm{D}$ hydrogel), rather than ensuring that bacteria can grow and interact as a community. Moreover, current printing methods typically have a resolution at the millimetre scale rather than the micrometre scale at which natural communities appear often to be structured. Here, we present a high-resolution droplet printing method that allows us to position interacting microbes in specific patterns in submillimetre arrays. With this, we are able to manipulate and study the ecology of microbial communities patterned at micron scales (Fig. 1). Our experiments reveal that changing the arrangement of bacterial genotypes across these fine scales can be critical for ecological outcomes.

\section{Results}

A new method to print patterned microbial communities. Our method works by piezo injection of tailored 'bioinks' comprising bacterial cells $\left(E\right.$. coli,$\approx 10^{8}$ cells $\left.\mathrm{mL}^{-1}\right)$, molten agarose $(1.5 \% \mathrm{w} / \mathrm{v})$ and lysogeny broth (LB) medium into an oil/phospholipid solution at $37^{\circ} \mathrm{C}$. The method generates $110-\mu \mathrm{m}$-diameter droplets $(\approx 70$ cells per droplet), which are deposited into $2 \mathrm{D}$ patterns by line-by-line printing (Fig. 1a). The droplets are initially surrounded by monolayers of phospholipid, which form bilayers on contact with one another, thereby creating a stabilised, support-free structure $^{40,41}$ (Fig. 1a). The resulting array is then gelled, and the lipid bilayers removed by the addition of an oil (silicone oil AR20, which causes the lipid to precipitate) to create a final printed community of bacteria in agarose suspended in LB medium ('Methods') (Fig. 1a, c-f). Within the printed community, bacteria grew from single-cell dispersions (with starting 2D centre-to-centre distances of $18 \pm 2 \mu \mathrm{m}$ ) into $3 \mathrm{D}$ microcolonies (with median diameters of $15(10-21) \mu \mathrm{m}$ ) over $18 \mathrm{~h}$ of growth (see Supplementary Fig. 1 and Supplementary Methods 1 for further characterisation of printed arrays). To validate the method, we printed two fluorescently labelled strains of E. coli. This demonstrated the ability to print specific patterns and, with them, to vary the amount of genetic mixing (defined by a segregation index $(S I)^{16}$, see 'Methods' and
Supplementary Fig. 2) at the scale of the arrays (Fig. 1g). Importantly, the calculated SI of our printed arrays matched well with the theoretical SI of the respective printing maps (Fig. 1h), and the imposed patterns did not impact the frequencies of strains that differ only in the fluorophore that they carry (Fig. 1i) (Supplementary Fig. 2 and Supplementary Methods 1.2). With this method, therefore, we can systematically alter the spatial arrangement of bacterial strains across naturally relevant scales to study how they interact and grow.

Competition between toxinogenic and susceptible cells. We next sought to test whether this spatial structure is important for the ecology of interacting bacteria. To do this, we studied a common ecological interaction in the mammalian gut: interference competition between strains of $E$. coli that produce protein toxins known as colicins ${ }^{24,42-45}$. While colicin production can be critical for survival, there is diversity in the types of colicins carried by E. coli strains, and many strains carry none at all-suggesting that colicin release is not always beneficial $^{44}$ (Supplementary Methods 2.1). We began by performing two-way competitions between susceptible non-colicinproducing strains $(\mathrm{S})$ and a range of colicin-producing strains $(\mathrm{P})$ in printed communities at different SI values (Fig. 2) (see Table 1 for strains used). Theory suggests that genetic mixing can favour colicin producers, by giving them more access to susceptible cells. Conversely, increasing spatial structure has the potential to isolate producer genotypes from susceptible genotypes, which might protect susceptible genotypes if the competition is restricted to the boundaries between genotypes (Fig. $2 \mathrm{~b}, \mathrm{c})^{46-48}$. These predictions are borne out in experiments with bacteriocins performed at large spatial scales ${ }^{23,49}$. However, it was far from clear whether the micron-scale spatial structure would have similar effects in our experiments. Colicins are released from cells (they do not remain attached), will easily diffuse through agar ${ }^{26,49}$ and are highly toxic, killing with single-hit kinetics ${ }^{50,51}$. These features of colicin biology mean they are able to diffuse and kill across the millimetre-to -centimetre scale, which might overwhelm any structure at the micron scale.

In spite of the potentially long-range activity of colicins, we found that altering spatial structure across the micron scale had significant effects on the outcome of competition between the bacteria. For all but one of the colicin types (E8), the introduction of fine-scale spatial structure enabled a distinct patch of the susceptible strains to persist (Fig. $2 \mathrm{~d}-\mathrm{h}$ ). The strength of this effect reflects the relative ability of each colicin strain to kill susceptible strains ${ }^{49,52}$ (Fig. $2 \mathrm{a}$ and Supplementary Fig. 3d-f). As might be expected, the more potent killers were less affected by 
a

\begin{tabular}{|c|c|c|c|c|c|}
\hline Strain & Toxin regulation & Action of toxin & Autoinduction & Activates production & Killing rank ${ }^{1}$ \\
\hline$\overparen{E 8}$ & SOS controlled & DNA damage & Yes & Yes & 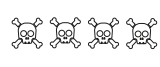 \\
\hline E2 & sos controlled & DNA damage & Yes & Yes & $\log _{0} \mathrm{log}_{000} 800$ \\
\hline 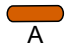 & sos controlled & Membrane disruption & No & No & 900000 \\
\hline$\overbrace{\mathrm{E} 7}$ & SOS controlled & DNA damage & No & Yes & 200 \\
\hline
\end{tabular}

b

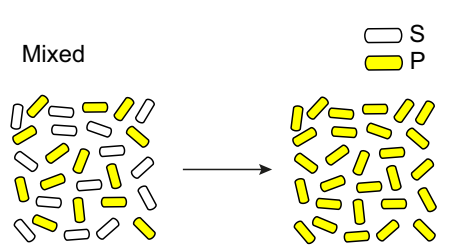

C

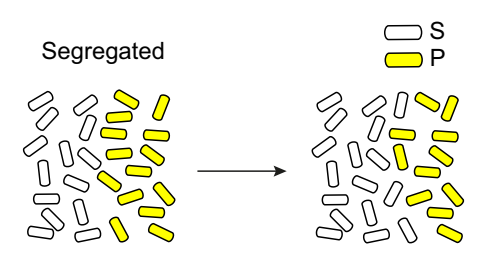

d Segregation index $(S I)$

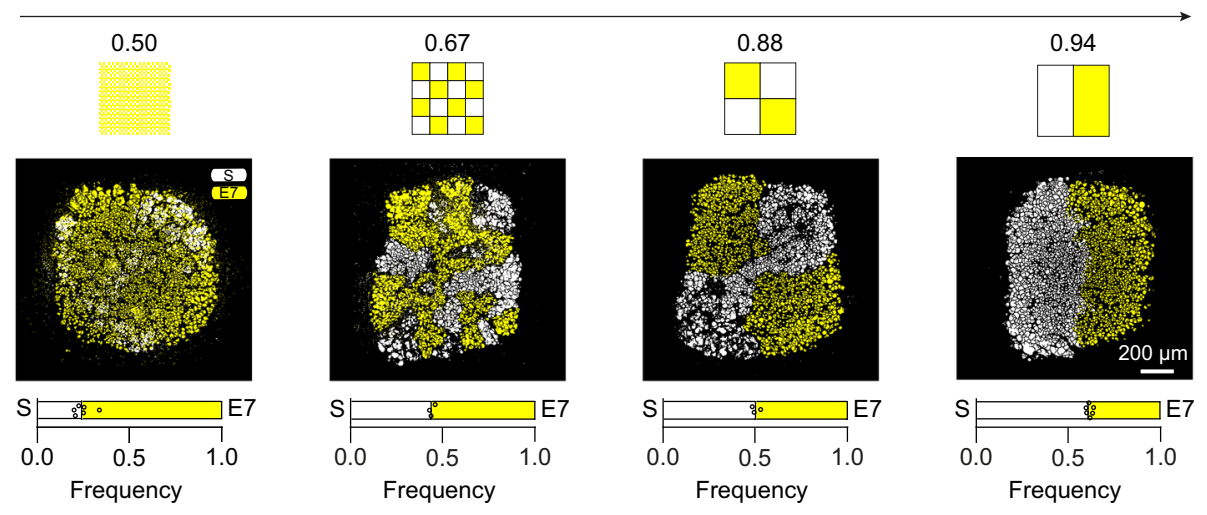

e
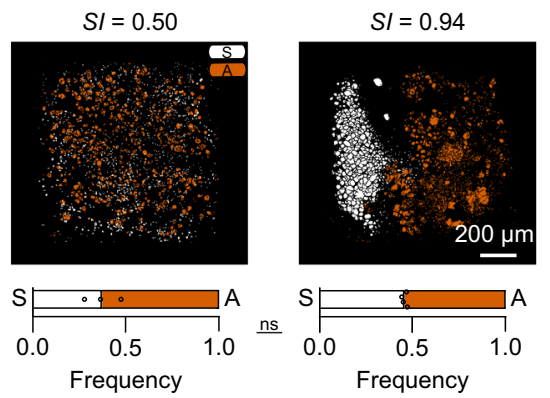

g
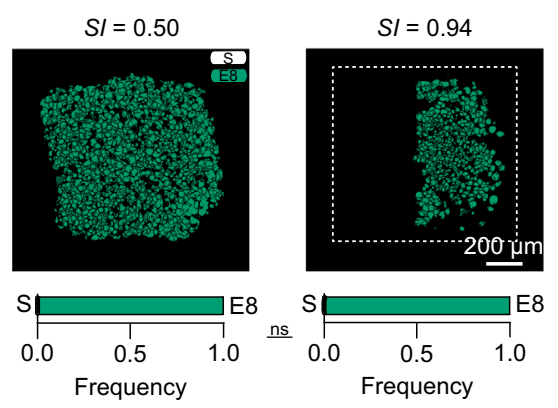

spatial structure, with the colicin E8 producer killing off the susceptible cells irrespective of whether there was structure (Fig. 2g). E8 is known to be both a potent colicin and one that is produced at high levels due to autoinduction, whereby producing cells promote toxin production in clonemates (Supplementary Fig. 3e). For all the other strains, we found that spatial structure

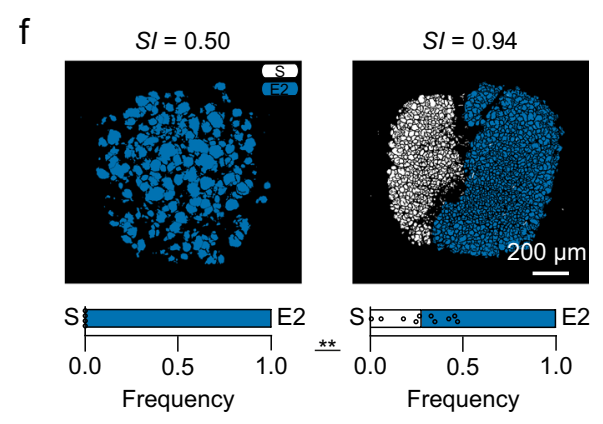

$\mathrm{h}$
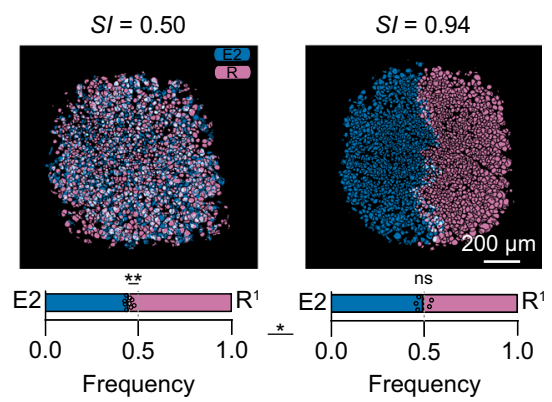

creates an ecological refuge $\mathrm{e}^{53}$ for susceptible cells. Even though the refuge is only a few hundred microns across, it allowed susceptible cells to better survive competition with toxinproducing strains for two of the combinations. For E7, this effect was so strong that the susceptible strain was able to outgrow the colicin producer when printed side by side (Fig. $2 \mathrm{~d}, f_{S}=0.65 \pm$ 
Fig. 2 Micron-scale structure shapes competition between susceptible and colicin-producing strains by creating ecological refuges. a The characteristics of each colicin-producing strain used in this study. 'The 'killing rank' ranks the ability of each of the colicin-producing strain to kill colicinsusceptible strains, see refs. 49,52 and data therein. b, c A schematic hypothesis, of how susceptible and colicin-producer frequencies change over time, in a genetically mixed spatial structure $(S I=0.50)(\mathbf{b})$, and in a genetically segregated spatial structure $(S I=0.94)$ (c), if susceptible growth rates outweigh the cost of toxin production. d, Segmented fluorescence images of S cells (white) and E7 cells (yellow) in communities printed at an initial SI of $0.50(n=6), 0.67(n=3), 0.88(n=3)$ and $0.94(n=6)$ with accompanying printing maps. A Kruskal Wallis test showed a statistically significant relationship between the change in frequencies of $S$ with $S I$ (Kruskal-Wallis statistic: 15.63, $P<0.001$, see Supplementary Table 2 for the statistical test). e-g Segmented fluorescence images of S cells (white) and A cells (vermillion) ( $n=3$ and $n=4$ for $S I=0.50$ and 0.94 , respectively) (e), and E2 cells (blue) ( $n=4$ and $n=10$ for $S I=0.50$ and 0.94, respectively) (f), and E8 cells (bluish-green) ( $n=7$ and $n=7$ for $S I=0.50$ and 0.94 , respectively) (g), in communities printed at an initial $S I=0.50$ and 0.94. $\mathbf{h}$ Segmented fluorescence images of E2 cells (blue) and $\mathrm{R}^{1}$ cells (reddish-purple) in communities printed at an initial $S /$ of $0.50(n=9)$ and $0.94(n=6)$. In $\mathbf{d}$-h, each fluorescently segmented image was taken after $18 \mathrm{~h}$ of competition. Below each fluorescently segmented imaged is a stacked bar chart of the frequencies of strains in the array. Each data point represents a biologically independent replicate; the mean frequencies of each strain are where the bars meet. In $\mathbf{e}-\mathbf{h}$, unpaired Mann-Whitney tests were performed to assess the statistical significance of the changes in frequencies of competing strains at different $S /$ values. For $\mathbf{e}, P=0.6286$; for $\mathbf{f}, P=0.0020$; for $\mathbf{g}$, $P=0.4462$; for $\mathbf{h}, P=$ 0.0336 (see Supplementary Tables 3 for statistical tests). In $\mathbf{h}$, one-sample $t$ and Wilcoxon tests showed a statistically significant $(P=0.0039)$ and nonsignificant $(P>0.6250)$ difference between the median frequencies of $E 2$ and $R^{1}$ at $S I=0.50$ and 0.94 , respectively (see Supplementary Tables 3 for statistical tests).

Table 1 Strains used in this study.

\begin{tabular}{|c|c|c|c|c|}
\hline Strain and genotype & Abbreviation & Toxin & Resistance to colicins & Colour code \\
\hline BZB1011 & $S$ & None & No & 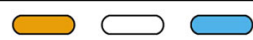 \\
\hline BZB1011 immE2 & $R^{2}$ & None & Yes-colicin E2 & 5 \\
\hline BZB1011 pColE7 & E7 & Colicin E7 & No & $\hookrightarrow$ \\
\hline BZB1011 pColE2 & E2 & Colicin E2 & No & $\hookrightarrow$ \\
\hline BZB1011 immE2 pColE2 & 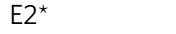 & Colicin E2 & No & $\hookrightarrow$ \\
\hline
\end{tabular}

Each colicin-producing strain is immune to its cognate toxin. For BZB1011 (S), the orange and sky blue colour codes are used to represent S cells expressing sfGFP and mRFP1, respectively, in Figs. 1 and 4 . The white colour code represents $S$ cells in Figs. 2 and 3.

0.02 at $S I=0.94)$. Counts of colony-forming units confirmed that the imaged susceptible cells in the printed arrays were viable, despite the presence of the toxin producer (Supplementary Fig. 3i). Exploring the case of E7 in more detail revealed a graded response to spatial structure, where progressively decreasing spatial structure (decreasing SI) led to a progressive increase in the abundance of the E7 colicin producer (Fig. 2d). At high genotypic mixing, the outcome of the competition was reversed, where now the toxin producer outcompeted the susceptible strain (Fig. $2 \mathrm{~d}, f_{S}=0.24 \pm 0.05$ at $S I=0.50$ ).

We also found an effect of spatial structure when a colicin producer strain competes with a colicin-resistant strain $\left(\mathrm{R}^{1}\right)$ rather than a susceptible strain (Fig. $2 \mathrm{~h}$ ). The colicin producer has a lower growth rate due to the costs of colicin production (Supplementary Fig $3 g-h$ ). However, this growth disadvantage only translates to an ecological disadvantage in the absence of spatial structure, i.e., when the two strains are well mixed $\left(f_{E 2}=\right.$ $0.46 \pm 0.02$ at $S I=0.50)$. When growing side-by-side in a structured community, the colicin producer reaches the same abundance as the resistant strain, despite its slower growth rate. We saw the same effect of spatial structure for another strain combination ( $\mathrm{S}$ and $\mathrm{R}^{1}$ ) that also lacks any toxin-mediated competition (Supplementary Fig. 4c). In these experiments, the micron-scale segregation of the two strains shifts competition to occur more within strains than between strains. As a result, the negative effects of inter-strain competition on a slower-growing strain are weakened. While our focus is interference competition (via toxins), we find that exploitative competition (mediated by differences in growth rate) is also affected by the introduction of spatial structure in the printed arrays.
Competition between toxinogenic strains. We have shown that the arrangement of bacteria at the submillimetre scale is important for the outcome of both interference and exploitative competition. Moreover, as predicted by both ecological and evolutionary theory, our results suggest that the key effect of printing strains side by side-as opposed to well mixed-is to weaken interactions (Fig. 2b, c) $23,54,55$. We next explored the importance of positioning for competition between pairs of toxin-producing strains, which are each immune to their own toxin but able to kill the other (Fig. 3). At first, these appeared to follow the same pattern as the previous (producer vs susceptible) experiments. In one (E2 and E7), we saw the same refuge effect with spatial structure, where the strain (E7) that is eliminated under mixed conditions can persist when printed side by side with the more dominant strain (E2) (Fig. 3a). The dominance of E2 is expected because a higher proportion of E2 cells make colicins than E7 cells due to autoinduction ${ }^{56,57}$. In another case, one strain (A) eliminated the other (E2) irrespective of spatial structure (Fig. 3b). Here, the potency of colicin A cells is expected because E2 is a DNase that activates the SOS response, which activates colicin A expression. By contrast, A does not activate E2 expression because colicin A targets membrane integrity rather than DNA (Fig. 2a and Supplementary Fig. 3f $)^{26,52,58}$. However, a third combination (E2 and E8) had a surprising outcome (Fig. 3c). Here, without spatial structure, the dominant strain E8 eliminated E2 as though E2 were simply a susceptible strain. By contrast, with spatial structure $(S I=0.94)$, both strains were almost completely eliminated, something not seen when these strains grow side-by-side at larger distances on agar plates ${ }^{49}$. 
a

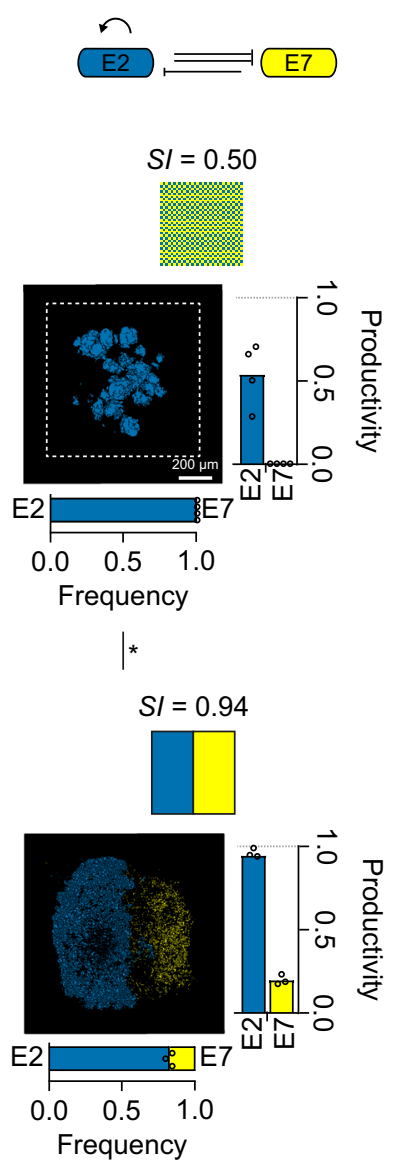

b

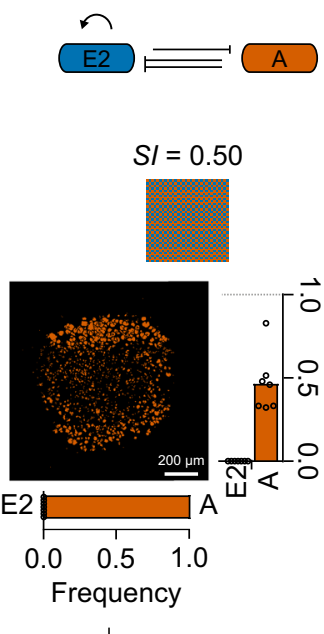

Ins

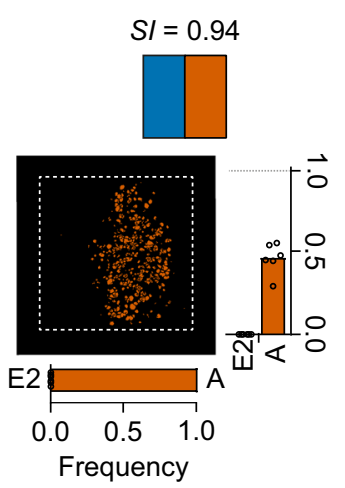

C

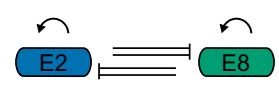

$S I=0.50$
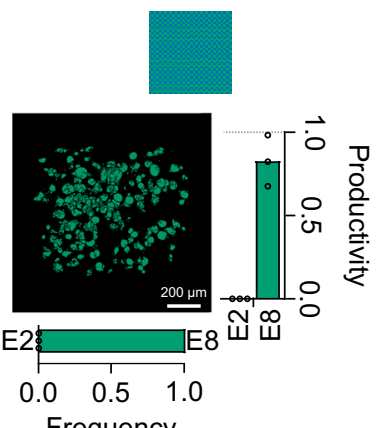

Frequency

*

$S I=0.94$
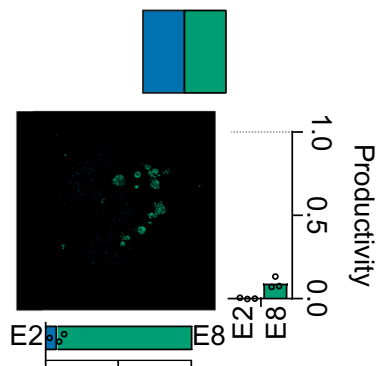

$0.0 \quad 0.5 \quad 1.0$

Frequency d

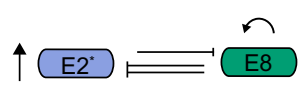

$S I=0.50$
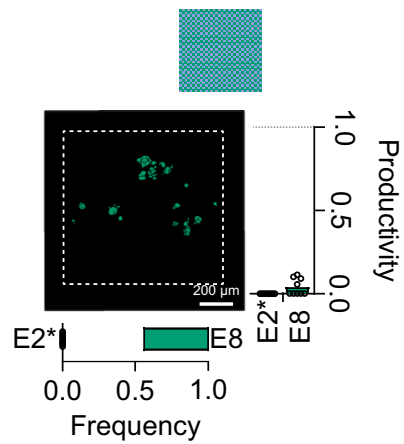

*

$S I=0.94$
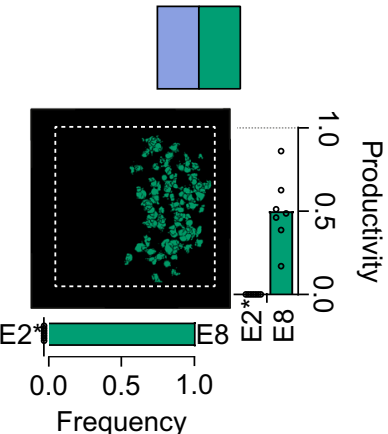

Fig. 3 Micron-scale structure shapes competition between colicin-producing strains and can drive mutual destruction. a-d Competition schematics followed by the corresponding segmented fluorescence images of E2 cells (blue) and E7 cells (yellow) $(n=4$ and $n=3$ for $S I=0.50$ and 0.94 , respectively) (a), E2 cells and A cells (vermillion) ( $n=7$ and $n=6$ for $S I=0.50$ and 0.94 , respectively) (b), E2 cells and E8 cells (bluish-green) ( $n=3$ and $n=3$ for $S I=0.50$ and 0.94 , respectively) (c) and E2* cells (bluish-grey) and E8 cells ( $n=9$ and $n=7$ for $S I=0.50$ and 0.94 , respectively) (d) in genetically mixed $(S I=0.50)$ and fully segregated $(S I=0.94)$ printed communities after $18 \mathrm{~h}$ of competition. In the bacterial warfare schematics, the curly arrows represent autoinduction, the single- inhibition arrows represent lower aggression, the double-inhibition arrows represent higher aggression and the vertical arrow represents a faster growth rate. Above each segmented fluorescence image is the corresponding printing map. Below each segmented fluorescence image is a stacked bar chart of the frequencies of strains in each printed array after $18 \mathrm{~h}$ of competition. Each data point is a biologically independent replicate, and the mean frequencies of each strain are denoted where the bars meet. The mean frequency of E8 in E2* vs E8 at $\mathrm{SI}=0.50$ (d) is shown as the length of the bar and the data points denote the frequencies of E2*. To the right of each segmented fluorescence image is a bar chart of the productivities of strains in printed arrays. Each data point is a biologically independent replicate and the mean productivities of each strain are denoted by the heights of the bars. In a-d, unpaired Mann-Whitney tests were performed to assess the statistical significance in the changes in frequencies of competing strains at different $S /$ values. For $\mathbf{a}, P=0.0286$; for $\mathbf{b}, P>0.9999$; for $\mathbf{c}, P=0.0286$; for $\mathbf{d}, P=0.0337$ (see Supplementary Tables 4 for statistical tests). In a-d, the term 'productivity' ( $p$ ) of a genotype $a$ in a printed array after $18 \mathrm{~h}$ of competition is defined as $p=A_{d} / A_{S}$, where $A_{S}$ is the total cross-sectional area that a susceptible genotype occupies after $18 \mathrm{~h}$ of competition (at the same starting density and spatial pattern as genotype $a$ ), but without interference competition.

We next sought to understand how spatial structure could enhance competition, and moreover do it to the extent that both populations collapse. We hypothesised that the answer lay in the fact that both of these strains exhibit autoinduction of colicin production. Similar to the effects of quorum sensing, this density-dependent regulation occurs because the import of a clonemate's DNA-damaging colicin increases a cell's probability of colicin release (Supplementary Fig. 3e). Autoinduction can have strong effects on competition between colicin strains ${ }^{49}$. In our experiments, we hypothesised that spatial structure provided E2 cells with enough refuge to reach a sufficient cell density to activate collective colicin production through autoinduction, thereby allowing them to inhibit E8 cells more strongly. To explore this, we studied competitions between E8 and an E2 strain engineered to lack autoinduction in colicin production (E2*, see 'Methods') (Fig. 3d). As predicted, this greatly reduced the impact of E2 on E8 in the presence of spatial structure. Moreover, the effects of the spatial structure were reversed, with mutual destruction of the two competitors now occurring under mixed conditions without spatial structure. This ability of the engineered E2* strain to eliminate E8 under mixed conditions is likely to stem from the relatively high growth rate of E2* (Supplementary Fig. 3g, h), which allows it to rapidly establish itself in mixed arrays. In sum, the impact of the spatial structure depends on whether E2 does, or does not, perform autoinduction. Moreover, in both cases, we see a strong effect where the printed pattern determines whether one strain thrives or both are largely eliminated. 
Three-genotype printing explains how 'microrefuges' form. The impacts of autoinduction demonstrate that fine-scale structure can have surprising and complex effects on bacterial interactions. Nevertheless, one effect that is commonly seen is that spatial structure creates a refuge, with subordinate strains better able to persist with spatial structure than without it. We sought, therefore, to understand the mechanistic basis of this refuge effect, using prints of three different types of bioinks to explore the interface between a colicin E2 producer and a susceptible strain (Fig. 4a). Printing cell-free agarose between an E2 strain and a susceptible strain removed the refuge effect, suggesting that the distribution of colicins was not limited by diffusion across the printed array (Fig. 4e). This result implied that the susceptible cells closest to the E2 producer were somehow interrupting the diffusion of colicins across the array. We hypothesised that this could occur if susceptible cells bind and thereby 'mop up' colicin molecules as they pass ${ }^{59}$. To explore this, we engineered a colicinresistant strain that lacks the BtuB receptor for colicin E2 (Table 1, Fig. 4b and Supplementary Fig. 4a) (see Supplementary Methods 2.2). As predicted by our model, the refuge effect was eliminated even though there were cells growing next to the colicin producer (Fig. 4f). However, the BtuB mutation also makes the cells resistant to colicin (Supplementary Fig. 4b), such that the lack of protection could be linked in some way to the lack of cell death from E2 activity. To exclude this possibility, we engineered a strain that carries BtuB, but which is resistant to colicins via cytoplasmic expression of the E2 immunity protein (Table 1, Fig. 4b and Supplementary Fig. 4a). This strain was not affected by the colicin of the E2 producer (Supplementary Fig. 4b) but did provide protection (Fig. 4g). We conclude, therefore, that binding of diffusing colicins by intoxicated cells is critical to the refuge effect. More generally, these experiments highlight the importance of processes that counteract the effects of diffusion at these scales, whether it be by binding, importing, or digesting solutes.

\section{Discussion}

The ecological interactions within microbial communities are central to their properties and impacts ${ }^{5,7}$. However, the fine spatial scales at which microbes position and interact are a challenge for experimental microbiology. Here we have presented a method for arranging microbial genotypes in defined $2 \mathrm{D}$ arrays with micronscale resolution. This method allowed us to establish a causal link between the arrangement of bacterial strains at these fine scales and ecological outcomes. We find that spatial structure impacts the outcome of both interference and exploitative competition. Moreover, the fine-scale structure can shift the outcome of competition from one strain dominating to another, and it can be the difference between one strain thriving and mutual destruction. A key principle that emerges across our experiments is that spatial segregation is often protective and limits the effects of one strain on the other. We show that for colicin E2, this is explained by the ability of susceptible cells to bind the toxin rather than by diffusion limitation. The extent of such refuge effects-and whether coexistence is stable or transitory-is likely to depend on a number of factors that we have not explored here. These factors include the length of the time that strains grow together, the turnover in nutrients and the initial frequencies of strains, which are all interesting targets for future work.

We find that one cannot simply translate results on the effect of spatial structure from coarse to fine scales. The outcomes we see in our arrays can be very different to those seen at larger scales. In particular, the conditions under which we observe mutual destruction (Fig. 3c) correspond to conditions that allow coexistence at a larger scale ${ }^{49}$. Nevertheless, many of our other findings mirror the conclusions from experiments at larger spatial scales ${ }^{23,60}$ where spatial segregation is well known to limit competition and promote coexistence. Our work, therefore, demonstrates that space still matters when one considers patterning at the fine scales that appear more typical in nature. Our findings also fit well with a large body of work on bacterial biofilms, which emphasises how both the binding and breakdown of solutes can generate strong gradients over small spatial scales, even when diffusion is not itself limiting $32,33,61-64$. The commonness of these micron-scale solute gradients suggests that the effects we have documented here will be important across many species and ecological interactions. The manipulation of fine-scale spatial structure, therefore, has significant potential for both understanding and controlling microbial communities.

\section{Methods}

Preparing aqueous phases. Phosphate-buffered saline (PBS) $(1 \times, \mathrm{pH} 7.4$, Gibco) was used as purchased. Lysogeny broth Miller (LB-Miller) medium was prepared by adding $10 \mathrm{~g}$ of tryptone (BD Difco ${ }^{\mathrm{TM}}$ ), $5 \mathrm{~g}$ of yeast extract (BD Difco ${ }^{\mathrm{TM}}$ ) and $10 \mathrm{~g}$ of sodium chloride (Fischer) to $1 \mathrm{~L}$ of Milli- $\mathrm{Q}^{\circledast}$ water and autoclaving. $5 \times \mathrm{M} 9$ medium (Sigma-Aldrich) without a carbon source $\left(12.8 \mathrm{~g} \mathrm{~L}^{-1} \mathrm{Na}_{2} \mathrm{HPO}_{4} \cdot 7 \mathrm{H}_{2} \mathrm{O}, 3 \mathrm{~g} \mathrm{~L}^{-1}\right.$ $\mathrm{KH}_{2} \mathrm{PO}_{4}, 0.5 \mathrm{~g} \mathrm{~L}^{-1} \mathrm{NaCl}, 1 \mathrm{~g} \mathrm{~L}^{-1} \mathrm{NH}_{4} \mathrm{Cl}, 2 \mathrm{mM} \mathrm{MgSO}_{4}$ and $0.1 \mathrm{mM} \mathrm{CaCl}_{2}$ ) was dissolved in Milli- $\mathrm{Q}^{\circledast}$ water, autoclaved and filtered through $0.22-\mu \mathrm{m}$ polyethersulfone membrane (Millex-GP Syringe Filter Unit). LB-Miller agar solutions (molten) were prepared by combining LB-Miller medium with agar (final concentration of $1.5 \% \mathrm{w} / \mathrm{v})\left(\mathrm{BD} \mathrm{Difco}^{\mathrm{TM}}\right.$ ) and autoclaving. $2.0 \% \mathrm{w} / \mathrm{v}$ of ultra-lowgelling-temperature (ULGT) agarose (Sigma-Aldrich) was prepared by dissolving $100 \mathrm{mg}$ in $5 \mathrm{~mL}$ of LB-Miller medium and autoclaving. The hydrogel was kept molten by keeping the solution in a static incubator at $37^{\circ} \mathrm{C}$. Molten solutions were only used for a week. Antibiotics were dissolved in Milli- $\mathrm{Q}^{\oplus}$ water, filter-sterilised $\left(0.22-\mu \mathrm{m}\right.$ polyethersulfone membrane) and frozen $\left(-20^{\circ} \mathrm{C}\right)$ as stock solutions at $100 \mathrm{mg} \mathrm{mL}^{-1}$ for ampicillin and $30 \mathrm{mg} \mathrm{mL}^{-1}$ for kanamycin (Sigma-Aldrich).

Preparing lipid/oil solutions. Lipids were purchased from Avanti ${ }^{\oplus}$ Polar Lipids in powder form and stored at $-80^{\circ} \mathrm{C}$. Undecane and silicone oil AR20 (SigmaAldrich) were filtered before use through 0.22 - $\mu \mathrm{m}$ filters (Corning ${ }^{\oplus}$ ) under vacuum. An optimised lipid/oil solution was prepared for printing ${ }^{65}$. Lipid films were prepared by bringing ampoules to room temperature and dissolving in anhydrous chloroform (Sigma-Aldrich) to make a chloroform/lipid solution at lipid concentrations of $25 \mathrm{mg} \mathrm{mL}^{-1}$. Chloroform/lipid stock solutions were used immediately. Using glass syringes (Hamilton ${ }^{\circledast}$ ), $45 \mu \mathrm{L}$ and $20 \mu \mathrm{L}$ of lipid stock solutions 1,2-diphytanoyl-sn-glycero-3-phosphocholine (DPhPC) and 1-palmitoyl-2-oleoylsn-glycero-3-phosphocholine (POPC), respectively, were transferred into a 7-mL, isopropanol-cleaned, Teflon-capped glass vial (Supleco ${ }^{\circledast}$ ). The lipid/chloroform solution was evaporated under a slow stream of nitrogen while rotating by hand to produce an even lipid film. The film was dried under vacuum for $24 \mathrm{~h}$, then stored under house nitrogen at $-80^{\circ} \mathrm{C}$ until use. When required for printing, films were left at room temperate for $30 \mathrm{~min}$, then $2 \mathrm{~mL}$ of a pre-mixed solution of undecane and silicone oil AR20 (35:65 by volume) was added to the film, followed by sonication (Branson 2800 ultrasonic bath $230 \mathrm{~V}$ ) for $1 \mathrm{~h}$. The total concentration of lipids was $1 \mathrm{mM}$ with a molar ratio of DPhPC:POPC of 2:1. Lipid films were kept for a maximum of 2 months.

Construction of recombinant DNA. Plasmid and primers used in this study are listed in Supplementary Tables 15 and 17, respectively. All PCRs were performed using KOD Hot Start DNA polymerase (Novagen ${ }^{\oplus}$ ), following standard protocols Plasmids were assembled using one-step isothermal assembly (NEBuilder ${ }^{\circledast} \mathrm{HiFi}$ DNA Assembly Master Mix M5520AA). All constructs were sequenced to verify whether sequences were correct (Source BioScience). The plasmids pGRG25-Pmax: $s f g f p$, pGRG25-Pmax:mrfp1 and pGRG25-Pmax:immE2 plasmids were provided from Mavridou et al. ${ }^{49}$. The plasmids coding for the fluorescent proteins YPet (pBC11-Pyba):ypet) and mNeonGreen (pBC43-PybaJ:blFP-Y3) were provided by Olivier Cunrath. The plasmid coding for the IPTG-inducible expression of ImmE2 (pC001-Ptrc:immE2 ${ }^{66}$ ) was provided by Nick Housden and Colin Kleanthous. The generation of the plasmid from which ImmE2 is constitutively expressed (pTML9Pmax:immE2) was assembled from the pBC22-Pybaj:bfp backbone (a plasmid identical in sequence to the plasmids encoding the YPet and $m$ NeonGreen fluorescent proteins but expressing BFP) using the primers TML-P57 and TML-P58, the ImmE2 coding sequence from pC001-Ptrc:immE2 using the primers TML-P61 and TML-P62 and the promoter and RBS driving the expression of superfolder GFP in pGRG25-Pmax:sfgfp using TML-P59 and TML-P60. All the primers used in this study were generated using SnapGene ${ }^{\varpi}$.

Construction of bacterial strains. Bacterial strains used in this study are outlined in Table 1 and Supplementary Table 16. E. coli BZB1011 and BZB1011 pCol genotypes were provided from references ${ }^{49,67}$. Chromosomally labelled ( $\operatorname{Tn} 7$ insertion) sfGFP and mRFP1 BZB1011 strains and BZB1011 pCol genotypes were 
a

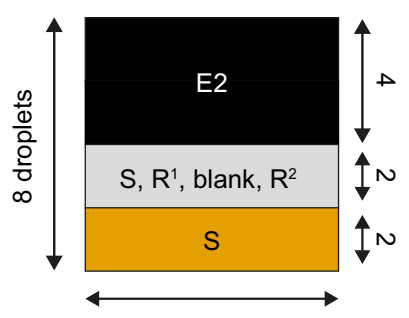

7 droplets b

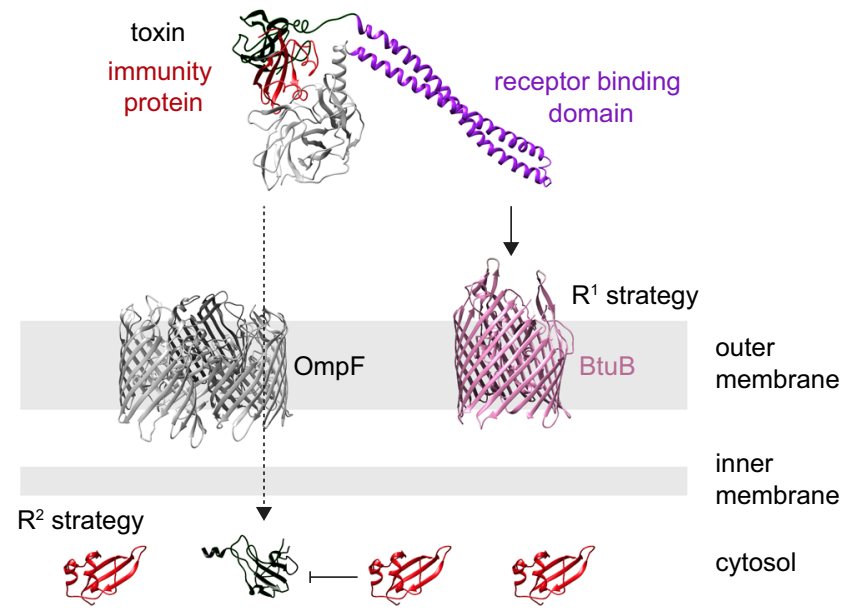

C

Map

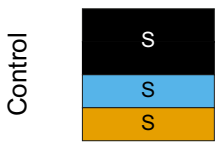

d

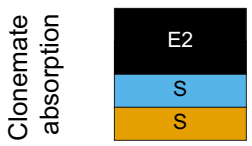

e

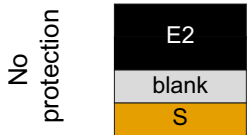

f

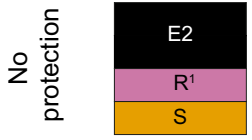

g

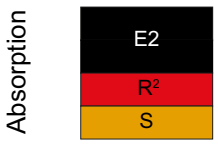

$\mathrm{Oh}$
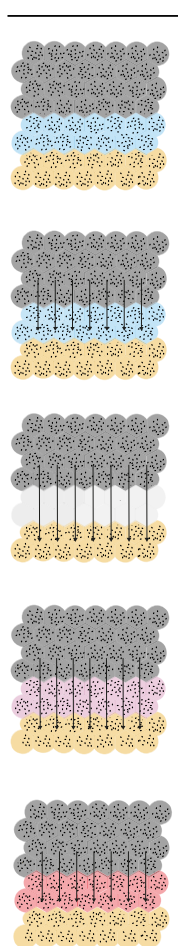

$18 \mathrm{~h}$
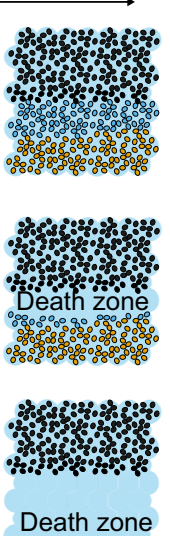

Death zone

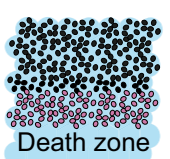

Death zone

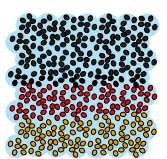

Printed (18 h)

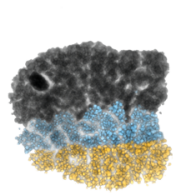

Productivity
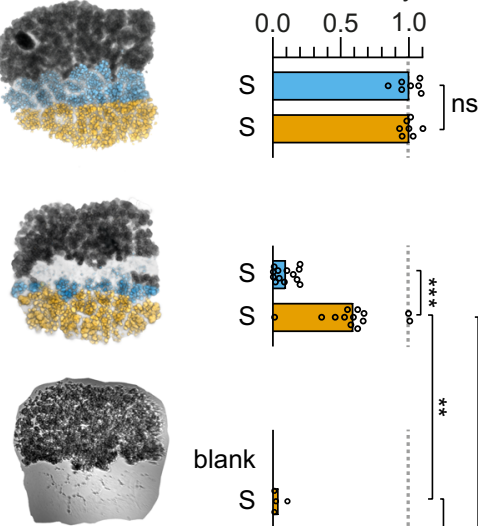

blank
$\mathrm{S}$
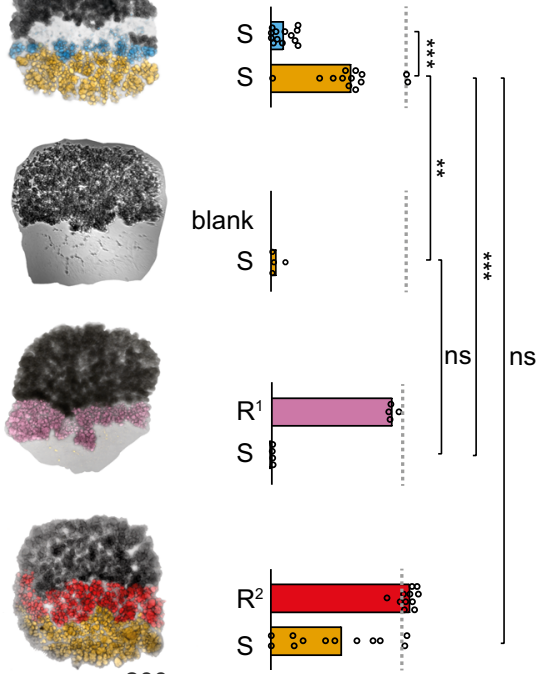

$200 \mu \mathrm{m}$

Fig. 4 Susceptible cells protect clonemates by binding incoming toxin. a Schematic of the printing map used for testing clonemate absorption. The producer strip (E2) consists of $7 \times 4 \times 1$ droplets (black), the changeable strip consists of $7 \times 2 \times 1$ droplet (grey) and the sensitive strip consists of $7 \times 2 \times$ 1 droplets (orange) in the $x, y$ and $z$ dimensions, respectively. $\mathbf{b} A$ schematic of the two resistance strategies used for creating $R^{1}$ and $R^{2}$. $R^{1}$ is resistant to colicins because of deletion of the BtuB receptor (which normally binds colicins). $R^{2}$ is resistant to colicins through constitutive expression of the cognate immunity protein, which binds and inactivates the toxin when it enters the cytosol. c-g Printing maps, competition schematics, composite bright-field and fluorescence microscopy images and bar charts of printed communities comprising three bioinks. $\mathbf{c}$ The control printed arrays containing three $\mathrm{S}$ strains $(n=$ 7). A Wilcoxon test showed that the median productivities of S-skyblue ( $\mathrm{rfp}$ ) and S-orange (S gfp) were non-significantly different $(P>0.9999$, see Supplementary Table 5 for the statistical test). d Printed arrays containing E2 cells (black) and two $S$ strains $(n=13)$. A Wilcoxon test showed that the median productivities of S-skyblue and S-orange were significantly different ( $P=0.0002$, see Supplementary Table 6 for the statistical test). e Printed arrays containing E2 cells, a strip of agarose not containing bacteria and S cells $(n=4)$. Mann-Whitney tests showed the median productivities of $\mathrm{S}$-orange in $\mathbf{e}$ and $\mathbf{d}$, and $\mathbf{e}$ and $\mathbf{f}$ were significantly $(P=0.0029)$ and non-significantly $(P=0.1143)$ different, respectively (see Supplementary Tables 7 for the statistical test). f Printed arrays containing E2 cells, $\mathrm{R}^{1}$ cells (reddish-purple) and S cells $(n=4)$. A Mann-Whitney test showed that the median productivities of $\mathrm{S}$-orange in d and $\mathbf{f}$ were significantly different $(P=0.008$, see Supplementary Table 8$)$. $\mathbf{g}$ Printed arrays containing E2 cells, $\mathrm{R}^{2}$ cells $(\mathrm{red})$ and $\mathrm{S}$ cells $(n=12)$. A Mann-Whitney test showed that the median productivities of S-orange in $\mathbf{d}$ and $\mathbf{g}$ were non-significantly different $(P=0.604$, see Supplementary Table 9$)$. In $\mathbf{d}-\mathbf{g}$, arrows on schematics represent the predicted colicin reach during the competition experiments (not to scale). In the bar charts, each data point is a biologically independent replicate and the height of the bars are mean productivity values. In $\mathbf{c}-\mathbf{g}$, the term 'productivity' $(p)$ of a genotype $a$ in a printed array after $18 \mathrm{~h}$ of competition is defined as $p=A_{a} / A_{S}$, where $A_{S}$ is the total cross-sectional area that a susceptible genotype occupies after $18 \mathrm{~h}$ of competition (at the same starting density and spatial pattern as genotype $a$ ), but without interference competition. 
provided from Mavridou et al. ${ }^{49}$. The BZB1011 $\Delta b t u B$ sfgfp::Tn7 or $m r f p 1:: \operatorname{Tn} 7$ strains were created by using the method described by Cianfanelli et al ${ }^{68}$. Briefly, the regions (700 base pairs) upstream and downstream of the $b t u B$ gene were amplified by PCR and joined together in the pFOK plasmid using the NEB ${ }^{\circ} \mathrm{HiFi}$ DNA Assembly Master Mix. In all, $5 \mu \mathrm{L}$ of the reaction was then transformed into chemically competent E. coli Jke201 (recovery in $1 \mathrm{~mL}$ of LB-Miller medium +100 $\mu \mathrm{M}$ diamino pumilic acid (DAP) and selected on LB-Miller agar plates $(1.5 \% \mathrm{w} / \mathrm{v})$ supplemented with $100 \mu \mathrm{M}$ DAP and $50 \mu \mathrm{g} \mathrm{mL}^{-1}$ kanamycin). Transformants were screened by colony PCR (GoTaq G2 polymerase) and sequencing (Source Bioscience) using the primers oOPC-614 and oOPC-615. Three clones carrying the correct plasmid (pTML8) were then conjugated with BZB1011 sfgfp::Tn7 and BZB1011 mrfp1::Tn7. Trans-conjugants for which a second recombination event had occurred were then counter-selected. Clones were finally verified by colony PCR and sequencing (by using the primers TML-P9 and TML-P10) for deletion of the btuB gene. The BZB1011 immE2::Tn7 pColE2 pBC11-PybaJ:ypet or pBC43$\mathrm{P} y b a J: b l F P-Y 3$ genotypes were generated by transforming competent BZB1011 immE2::Tn7 pColE2 cells (from Mavridou et al. ${ }^{49}$ ) with the respective plasmids, and by selecting for transformants on LB-Miller agar plates $(1.5 \% \mathrm{w} / \mathrm{v})$ supplemented with $30 \mu \mathrm{g} \mathrm{mL}^{-1}$ of kanamycin. The BZB1011 mrfp 1::Tn7 pC001-Ptrc: immE2 and BZB1011 mrfp1::Tn7 pTML-9-Pmax:immE2 genotypes were generated by transforming competent BZB1011 $m r f p 1:: T n 7$ with either pC001-Ptrc:immE2 or pTML-9-Pmax:immE2, and selecting for transformants on LB-Miller agar plates $(1.5 \% \mathrm{w} / \mathrm{v})$ supplemented with $100 \mu \mathrm{g} \mathrm{mL}-1$ of ampicillin.

Competent cell preparation and transformation. The strain for transformation was inoculated in LB-Miller medium overnight. The next day, the optical density at $600 \mathrm{~nm}\left(\mathrm{OD}_{600}\right)$ of the overnight culture was measured using a spectrophotometer (Thermo Scientific, Genesys 10 S UV-VIS). The overnight culture was then inoculated into $50 \mathrm{~mL}$ of LB-Miller medium to a final $\mathrm{OD}_{600}$ of 0.05 , and then incubated at $37^{\circ} \mathrm{C}$ (shaking at $225 \mathrm{rpm}$ ) until the $\mathrm{OD}_{600}$ reached $\approx 0.4$. Next, the cultures were split into centrifuge tubes $\left(25 \mathrm{~mL}\right.$ in each) and centrifuged at $4{ }^{\circ} \mathrm{C}$ for $10 \mathrm{~min}$ at $1734 \mathrm{~g}$. Following this, the supernatants were discarded, and each pellet was gently resuspended in $12.5 \mathrm{~mL}$ of $4{ }^{\circ} \mathrm{C} 100 \mathrm{mM} \mathrm{CaCl}_{2}+15 \% \mathrm{v} / \mathrm{v}$ glycerol solutions. After the addition of these solutions, cultures were left on ice for $45 \mathrm{~min}$. After this, cultures were again centrifuged at $4{ }^{\circ} \mathrm{C}$ for $10 \mathrm{~min}$ at $1734 \times$ g. Centrifuged pellets were recombined pairwise by resuspending one of the pellets in $5 \mathrm{~mL}$ of ice-cold $100 \mathrm{mM} \mathrm{CaCl}_{2}+15 \% \mathrm{v} / \mathrm{v}$ glycerol solution, and using this resuspension, the second pellet was resuspended. Following this, $200 \mu \mathrm{L}$ of competent bacteria were aliquoted into $1.5-\mathrm{mL}$ centrifuge tubes and directly frozen at $-80^{\circ} \mathrm{C}$.

To transform competent cells, $100 \mu \mathrm{L}$ of competent cells were thawed on ice. Once thawed, DNA ( $\approx 100 \mathrm{ng}$ for plasmids or $5 \mu \mathrm{L}$ of Gibson assembly reaction mixtures) was added to the cells. The cells were then kept on ice for $30 \mathrm{~min}$. Following this, the cells were heat-shocked by transferring the tube containing the cells and DNA into a $42{ }^{\circ} \mathrm{C}$ water bath for $45 \mathrm{~s}$ and then transferring the tube back on ice for $2 \mathrm{~min}$. The cells were then recovered by adding $900 \mu \mathrm{L}$ of LB-Miller medium and incubating for an hour at $37^{\circ} \mathrm{C}$ (shaking at $225 \mathrm{rpm}$ ). After one hour of recovery, $100 \mu \mathrm{L}$ of the cultures were plated on selective LB-Miller agar $(1.5 \% \mathrm{w} / \mathrm{v})$. The remaining $900 \mu \mathrm{L}$ were centrifuged for $1 \mathrm{~min}$ at $8000 \times g$, followed by discarding of the supernatant and resuspension of the pellet in $100 \mu \mathrm{L}$ of LB-Miller medium. The final $100 \mu \mathrm{L}$ were then plated on the corresponding selective LB-Miller agar $(1.5 \% \mathrm{w} / \mathrm{v})$. Both plates were then incubated overnight at $37^{\circ} \mathrm{C}$ in a static incubator and checked for transformants the following day.

Growth curves and analysis. Overnight cultures of the strains tested were normalised to an $\mathrm{OD}_{700}$ (optical density taken at $700 \mathrm{~nm}$ ) ${ }^{69}$ of 0.2 in PBS and washed twice. About $10 \mu \mathrm{L}$ of normalised cultures were added to the wells (containing 190 $\mu \mathrm{L}$ of LB-Miller medium) of a flat-bottom transparent 96-well plate (excluding the two first and two last columns, which were filled with $200 \mu \mathrm{L}$ of sterile Milli-Q ${ }^{\circ}$ water), bringing the initial $\mathrm{OD}_{700}$ to 0.01 . The layout of the plate was randomised using the CRUK PlateLayout tool (https://github.com/crukci-bioinformatics/ PlateLayout) for each biologically independent replicate $(n=3)$. Three wells were left uninoculated to calculate background $\mathrm{OD}_{700}$. The plate was then incubated at $37^{\circ} \mathrm{C}$ (shaking at $400 \mathrm{rpm}$, double orbital) in a plate reader (BMG Labtech Omega) for $24 \mathrm{~h}$, measuring $\mathrm{OD}_{700}$ every $5 \mathrm{~min}$.

Doubling times were calculated from the growth curves using a custom Python script. In brief, data were imported in Python dataframes, sorted and the mean of the technical replicates calculated. The mean of the biologically independent replicates was then calculated. The data were then plotted, and the doubling times calculated using the data points between OD 0.2 and 0.7 (exponential phase) and a custom script (https://doi.org/10.5281/zenodo.4328623). Lag-phase duration was calculated using DMFit 3.5 (https://www.combase.cc/index.php/en/8-category-en$\mathrm{gb} / 21$-tools $)^{70}$. Plate reader data were formatted to be used by DMFit using a custom Python script.

Growth inhibition assay. The resistance of BZB1011 $s f g f p:: T n 7 \Delta b t u B$, BZB1011 $m r f p 1:: T n 7 \Delta b t u B$, BZB1011 mrfp1::Tn7 pC001-Ptrc:immE2 and BZB1011 mrfp1:: Tn7 pTML-9-Pmax:immE2 strains to colicin E2 was assessed using a growth inhibition assay adapted from White et al ${ }^{71}$. Each strain to be tested and BZB1011 pColE2 were inoculated in $3 \mathrm{~mL}$ of LB-Miller medium and incubated overnight at $37^{\circ} \mathrm{C}$ (shaking at $225 \mathrm{rpm}$ ). The following day, the overnight cultures were diluted in LB-Miller medium to an $\mathrm{OD}_{600}$ of 0.05 and incubated at $37^{\circ} \mathrm{C}$ (shaking at 225 $\mathrm{rpm}$ ) until they reached an $\mathrm{OD}_{600}$ between 0.6 and 0.7 . In all, $200 \mu \mathrm{L}$ of the cultures were then added to molten soft LB-Miller agar $(0.75 \% \mathrm{w} / \mathrm{v}) \mathrm{kept}$ at $56^{\circ} \mathrm{C}$ and poured over LB-Miller agar plates $(1.5 \% \mathrm{w} / \mathrm{v})$. After the plates had dried, $2 \mu \mathrm{L}$ of serially diluted E2 overnight culture was spotted on the plates. Plates were then incubated at $37^{\circ} \mathrm{C}$ (static) overnight and imaged to check for inhibition zones or lack of inhibition zones (which determined resistance).

Preparation of bioinks. Genotypes were cultured directly from glycerol stocks (50\% v/v glycerol) in $4 \mathrm{~mL}$ of LB-Miller medium for $15 \mathrm{~h}$ (shaking at $250 \mathrm{rpm}$ ). From the overnight cultures, $20 \mu \mathrm{L}$ of each was added to $2 \mathrm{~mL}$ of fresh LB-Miller medium and cultured for $3 \mathrm{~h}$ (shaking at $250 \mathrm{rpm}$ ). Cultures were then normalised to $10^{9}$ cells $\mathrm{mL}^{-1}$ by centrifugation at $8000 \times g$ for $5 \mathrm{~min}$ and resuspended in 100 $\mu \mathrm{L}$ of fresh LB-Miller medium. Centrifugation, removal of the supernatant and addition of fresh LB medium $(100 \mu \mathrm{L})$ were repeated twice to remove any colicin in the supernatant. If 1:1 competitions were investigated at an SI of 0.50 , the two normalised bacteria cultures were combined at a 1:1 ratio $(50+50 \mu \mathrm{L})$. At any other SI (that required two or three nozzles for printing), a bioink was created per culture. To create the bioinks, $150 \mu \mathrm{L}$ of molten $2.0 \% \mathrm{w} / \mathrm{v}$ ULGT agarose in LBMiller medium $\left(37^{\circ} \mathrm{C}\right), 30 \mu \mathrm{L}$ of LB-Miller medium and $20 \mu \mathrm{L}$ of normalised culture were combined in PCR tubes and mixed by gently pipetting back and forward using a $200-\mu \mathrm{L}$ pipette to homogenise the solution for printing. Pipette tips (Corning ${ }^{\oplus} 1-200 \mu \mathrm{L}$ Filtered IsoTip ${ }^{\mathrm{m}}$ ) and PCR tubes were maintained at $37^{\circ} \mathrm{C}$ before homogenising the bioink.

Printing bacterial droplet networks containing bacteria. The functioning of the $3 \mathrm{D}$ droplet printer is outlined in our previous work ${ }^{41}$. In brief, a custom-built piezoelectric transducer $( \pm 130 \mathrm{~V})$ transmits controlled pressure impulses to a chamber filled with Milli- $\mathrm{Q}^{\infty}$ water. The chamber is connected to a glass nozzle (with a tip diameter of $\approx 150 \mu \mathrm{m}$ ) from which the aqueous printing solution is ejected (Supplementary Fig. 8). To prevent mixing of the printing solution with the water inside the chamber and nozzle, an undecane oil plug of $\approx 5 \mu \mathrm{L}$ was used to separate the two solutions. A quartz cuvette (Starna Scientific Ltd) with dimensions of $20 \times 10 \times 10 \mathrm{~mm}$ (length, width and height) was filled with $1 \mathrm{~mL}$ of lipid/oil solution and mounted on the micromanipulator. An IR heater (Beurer Ltd., $150 \mathrm{~W}$ ) was used to equilibrate the temperature of the nozzles and the quartz cuvette (from a fixed distance) to approximately $37^{\circ} \mathrm{C}$ over $30 \mathrm{~min}$. After equilibration, the bioink was loaded into the nozzle, and the tip was immersed into the lipid/oil solution contained in the quartz cuvette, which was positioned on a digitally controlled micromanipulator (PatchStar micromanipulator, Scientifica, 20-nm resolution). The micromanipulator movements and the piezo actuation were synchronised using a custom-made software developed in LabVIEW (National Instruments ${ }^{\mathrm{TM}}$ ). Printing was monitored using a side-on stereomicroscope (Nikon SMZ745T) and videos and pictures were acquired using a digital camera (Thorlabs DCC1645C) mounted on the microscope. For creating patterns at $S I=$ $0.67,0.80,0.88$ and 0.94 , a second nozzle was used simultaneously to the first. The second nozzle was normalised to the offset of the first nozzle so that the pattern could be printed line-by-line. For three bioinks, the two smaller strips were printed first using two nozzles followed by replacing the first nozzle with a new nozzle containing the third bioink for printing the larger strip. The third nozzle was aligned with a control droplet to complete the pattern.

\section{Creating printed arrays containing bacteria from printed droplet networks.} Once droplet networks were printed, the structures were left for $15 \mathrm{mins}$ at $37^{\circ} \mathrm{C}$ to allow the droplets to reach their equilibrium contact angles. Following equilibration, networks were moved to the fridge $\left(4^{\circ} \mathrm{C}\right)$ for $1 \mathrm{~min} 30 \mathrm{~s}$ to partially gel the ULGT agarose. Next, networks were moved from the fridge to ambient temperature $\left(22^{\circ} \mathrm{C}\right)$ and washed with silicone oil AR20 by initially removing $500 \mu \mathrm{L}$ of the lipid/oil solution and then adding $600 \mu \mathrm{L}$ of silicone oil AR20. Then, $600 \mu \mathrm{L}$ of the diluted lipid/oil solution were removed followed by addition of $600 \mu \mathrm{L}$ of silicone oil AR20. This was repeated two more times. The silicone oil washing step was performed to precipitate the lipids so that the tessellated droplets of partially gelled ULGT agarose could connect with each other. After washing, the networks were left for $5 \mathrm{~min}$ at ambient temperature to allow complete breaking of all bilayers and consequent connection of partially gelled ULGT agarose droplets. After $5 \mathrm{~min}$, the networks were moved to the fridge for $45 \mathrm{~min}$ to create a gelled block of LB-Miller ULGT agarose containing patterned bacteria (printed arrays). After $45 \mathrm{~min}$, each printed array was moved to individual containers filled with $600 \mu \mathrm{L}$ of LB-Miller media (Nunc ${ }^{\mathrm{TM}}$, Lab-Tek ${ }^{\mathrm{TM}}$ II Chamber Slide ${ }^{\mathrm{TM}}$ System (8 wells)) by hydrating the array in $0.5 \mu \mathrm{L}$ of LB-Miller medium (using a $0.5-\mu \mathrm{L}$ Hamilton syringe), followed by picking up the LB-Miller droplet containing the printed array (using a cut pipette tip $(20 \mu \mathrm{L})$ ) and pipetting the printed array into the container. Sterile 20- $\mu \mathrm{L}$ pipette tips were cut using a sterile scalpel (No. 21 Swann-Morton ${ }^{\circ}$ ). Printed arrays were encapsulated in LB-Miller medium and subsequently transferred into chambers by using a Leica ${ }^{\oplus}$ EZ4 Stereomicroscope with a $\times 16$ eyepiece.

Bacterial competition experiments within printed arrays and imaging of results. For competition experiments, printed arrays in LB-Miller media were 
incubated at $37^{\circ} \mathrm{C}$ for $18 \mathrm{~h}$. After $18 \mathrm{~h}$, printed arrays were washed with M9 medium to remove excess bacteria that grew out into solution from the printed arrays during the competition experiment. Within each compartment containing a printed array, $400 \mu \mathrm{L}$ of LB-Miller medium were removed and $200 \mu \mathrm{L}$ of $\mathrm{M} 9$ medium were added. Following this, $200 \mu \mathrm{L}$ of the medium were removed and another $200 \mu \mathrm{L}$ of M9 medium were added to further wash and remove the bacteria. Finally, printed arrays were picked up using a cut pipette tip $(20 \mu \mathrm{L})$ and transferred into individual containers containing $400 \mu \mathrm{L}$ of M9 media ( $\mathrm{Nunc}^{\mathrm{TM}}$, Lab-Tek ${ }^{\mathrm{TM}}$ II Chambered Coverglass (eight wells)). Printed arrays were left in M9 media for $10 \mathrm{~h}$ to allow the exchange of LB medium with M9 medium, required for imaging. Printed arrays were imaged using a Leica ${ }^{\circ}$ SP5 confocal microscope using a HC PL Fluotar $\times 10 / 0.30$ objective ( 0.3 numerical aperture), at excitation wavelengths of $405 \mathrm{~nm}$ and $546 \mathrm{~nm}$ and emission cut-offs at $420-520 \mathrm{~nm}$ and $625 \mathrm{~nm}$, respectively (exciting superfolder GFP, mRFP1, YPet and mNeonGreen), a $z$-step of $2.73 \mu \mathrm{m}$ and scanning speed of $400 \mathrm{~Hz}$.

Colony-forming units of printed arrays. Printed arrays were washed and transferred to $400 \mu \mathrm{L}$ of $\mathrm{M} 9$ medium after $8 \mathrm{~h}$ of competition. This time point was chosen because space in the printed arrays was saturated with $E$. coli within $8 \mathrm{~h}$ Next, printed arrays were moved to individual $1-\mathrm{mL}$ centrifuge tubes containing $200 \mu \mathrm{L}$ of M9 medium and melted at $55^{\circ} \mathrm{C}$ for $1 \mathrm{~min}$ in a thermomixer (Eppendorf ThermoMixer ${ }^{\oplus} \mathrm{C}$ ) shaking at $1000 \mathrm{rpm}$. Following this melting, the E. coli-containing solutions were serially diluted by 10,000 -fold $(100 \mu \mathrm{L}$ in $900 \mu \mathrm{L}$ of $\mathrm{M} 9$ medium). Following this, $10,000 \times$ diluted solutions were plated by beads on $1.5 \%$ w/v LB-Miller agar plates and then left to grow for $24 \mathrm{~h}$ at $37^{\circ} \mathrm{C}$ in a static incubator. After $24 \mathrm{~h}$, colonies were counted using a Zeiss PlanApo $\mathrm{Z} \times 0.5$ objective on an AxioZoom.V16 Zeiss microscope. Genotypes were recognised by fluorescence.

Flow cytometry of printed arrays. Printed arrays were washed and transferred to $400 \mu \mathrm{L}$ of M9 medium after $18 \mathrm{~h}$ of competition. Next, printed arrays were moved to individual $1-\mathrm{mL}$ centrifuge tubes containing $200 \mu \mathrm{L}$ of $\mathrm{M} 9$ medium and melted. The cell suspensions were diluted a further tenfold in M9 medium. Diluted cell suspensions were analysed on a BD Accuri C6 Flow Cytometer (Version 1.0.264.21) using 10,000 and 8000 as thresholds for the forward and side scatter parameters, respectively. For each experimental condition, 20,000 events were quantified per sample. A custom-written script was written on Rstusdio (Version 1.3.959) to analyse data. The population of bacteria was gated by considering only the events within the core of the cell population in order to minimise count biases (Supplementary Fig. 7c). This was calculated from the forward and side scatter dimensions. Cells that had a fluorescence intensity above $2^{9.5}$ were assigned as BZB1011 sfffp::Tn7. Cells below this were assigned as BZB1011 $m r f p 1:: \operatorname{Tn} 7$ (Supplementary Fig. 7d). Counts shown in Supplementary Fig. $2 \mathrm{c}$ are based on the first 3000 cells that met the selection criteria, which were used to calculate the frequencies of BZB1011 sfgfp::Tn7 and BZB1011 mrfp 1::Tn7. Contour plots were visualised using FlowJo 10.7.0 (Tree Star, Inc.).

Microcolony quantification by image analysis. $2 \mathrm{D}$ segmentation: $3 \mathrm{D}$ confocal images of printed arrays were projected into $2 \mathrm{D}$ using an average intensity projection (using $\mathrm{FIJ}^{72}$ software). The resulting $2 \mathrm{D}$ images were then segmented using a combination of ridge detection ${ }^{73}$, morphological watershed ${ }^{74}$ and intensity thresholding. This generated binary images of microcolonies. Each binary image was then used as a mask to extract each microcolony's position, orientation, length and width, as well as its brightness in the two fluorescence channels. Image segmentation and analysis were performed using MATLAB $^{\circ}$ (MathWorks ${ }^{\circ}$ ) (R2017a) with a custom-written user interface (FAST: https://doi.org/10.5281/ zenodo.4323627).

Print isolation: Some images of prints contained small pieces of detached debris and regions from other prints. To automatically remove these from downstream analyses, the size of each print was estimated and used to exclude these external microcolonies. In the first step of this process, the approximate centre of the print $(\bar{x}, \bar{y})$ was found by averaging the $x$ and $y$ coordinates of all microcolonies in the image. The average distance of each microcolony from $(\bar{x}, \bar{y})$ was then calculated as $\bar{r}$. The approximate side length of the print $L$ was then found as

$$
L=\frac{6 \bar{r}}{(\sqrt{2}+\log (1+\sqrt{2}))} .
$$

This was used to set a radial distance threshold on the detected microcolony positions, allowing the main print to be isolated from unrelated microcolonies. $(\bar{x}, \bar{y})$ was then recalculated excluding these microcolonies, providing a more accurate measure of the centre of the print.

Print registration: The above approximation of $L$ assumes that prints are perfectly square. To obtain a more accurate measure of the size of the rectangular prints, they were first registered to the $x-y$ coordinate system. This required finding an angle $\theta$ through which each print could be rotated to bring it into alignment with all other prints. The first stage of this process involved finding the convex hull of the print, and then measuring the distance between each point on the hull and $(\bar{x}, \bar{y})$. These values were then resampled onto a regularly spaced series of $N$ polar angles $\varphi_{n}$ measured from $(\bar{x}, \bar{y})$. The mean was then subtracted from the resulting series of values, resulting in a function $d(\varphi)$ that was positive at values of $\varphi$ where the outer boundary of the print was further-than-average away from the centre and negative at values of $\varphi$ where it was closer than average.

$d(\varphi)$ has peaks at values of $\varphi$ corresponding to each of the four corners of the print interleaved with troughs at values of $\varphi$ corresponding to the sides. Furthermore, $d(\varphi)$ is circular, with $d\left(\varphi_{1}\right)=d\left(\varphi_{\mathrm{N}+1}\right) . \theta$ could therefore be found from the phase of the Discrete Fourier Transform (DFT) on $d(\varphi)$ with wavenumber $k=4$. Explicitly,

$$
\theta=\frac{1}{4}\left(\pi-\arg \left(\sum_{n=0}^{N-1} d\left(\varphi_{n}\right) \cdot e^{-\frac{i 8 \pi}{N} n}\right)\right)
$$

The position of each microcolony was then rotated about $(\bar{x}, \bar{y})$ by $\theta$, and the size of the print in each direction estimated as the difference between the minimum and maximum $x$ and $y$ coordinates of the registered microcolonies.

Microcolony neighbour-neighbour distance estimation: Delaunay triangulation ${ }^{75}$ was applied to the positions of all microcolonies in the print. Microcolonies directly connected in the resulting triangulation were assigned as neighbours. Microcolonies forming the outer boundary of the print were therefore excluded when calculating the radial neighbour-neighbour distance profile.

3D segmentation: 3D segmentation of confocal microcolony data was performed using a generalisation of the algorithm used during $2 \mathrm{D}$ segmentation. Specifically, a rough segmentation of the initial array of voxel intensities $I(x, y, z)$ was first generated by applying a simple intensity threshold, allowing the bright microcolony-containing regions to be separated from the dark background. However, variations in background intensity and intermediate intensities of voxels between closely packed microcolonies prevented this approach from reliably isolating individual microcolonies within these regions.

To separate these closely packed microcolonies, we located 3D ridge-like features (e.g., blobs, sheets or tubes) that were dark relative to nearby microcolonies ${ }^{76,77}$. Initially, $I(x, y, z)$ was convolved with a Gaussian kernel $G(x, y$, $z, \sigma)$ of spatial scale $\sigma$ to isolate features at that scale:

$$
\tilde{I}(x, y, z, \sigma)=I(x, y, z) * G(x, y, z, \sigma)
$$

The second-order derivatives of $\widetilde{I}\left(\widetilde{I}_{x x}, \widetilde{I}_{x y}\right.$, etc.) were next used to construct the Hessian $H$ of the image at each voxel:

$$
H(x, y, z, \sigma)=\left[\begin{array}{lll}
\widetilde{I}_{x x} & \widetilde{I}_{x y} & \widetilde{I}_{x z} \\
\widetilde{I}_{y x} & \widetilde{I}_{y y} & \widetilde{I}_{y z} \\
\widetilde{I}_{z x} & \widetilde{I}_{z y} & \widetilde{I}_{z z}
\end{array}\right]
$$

$H$ contains information on the 3D features of scale $\sigma$ present within the image around position $(x, y, z)$. These features can be classified by finding the eigenvalues $\lambda_{1}, \lambda_{2}$ and $\lambda_{3}$ of $H$, where $\left|\lambda_{1}\right| \geq\left|\lambda_{2}\right| \geq\left|\lambda_{3}\right|^{76,77}$. However, as we were not concerned with the specific type of feature separating microcolonies, we generated a binary segmentation of the image simply by finding all voxels for which $\lambda_{1}$ was above a threshold value. This fine-grained mask was then combined with the initial rough segmentation using a voxelwise AND filter, generating the final segmentation.

Calculating segregation indices. We used a $S I$ to measure genetic mixing within printed arrays, and to quantify printing fidelity. SI was computed for printedcolony micrographs as follows:

1. Segmentation: Each micrograph pixel was assigned a genetic identity ('A', 'B' or 'None') by comparing its two fluorescence channel intensities, thresholded separately using Otsu's method ${ }^{78}$. Pixels in which both channels exceeded the intensity threshold were classified as containing neither cell type ('None').

2. Local SI: We computed a local segregation index $s_{i}$ for each A- or B-type pixel $i$, by comparing its genetic identity with those of neighbouring pixels. For a square neighbourhood of size $h, s_{i}(h)$ is defined as

$$
s_{i}(h)=\frac{1}{N_{i}(h)} \sum_{j=1}^{N_{i}(h)} g_{i}(j), \quad g_{i}(j)= \begin{cases}1, & \text { pixels } i \text { and } j \text { are kin } \\ 0, & \text { otherwise }\end{cases}
$$

where $N_{i}(h)$ is the number of A- or B-type pixels within $h$ rows or columns of focal pixel $i$. Thus, $s_{i}(h)$ is the fraction of $i$ 's neighbours that share its genotype. Note: for ease of image processing, here we are considering square neighbourhoods instead of the circular ones used previously ${ }^{19,71}$

3. Global SI: We defined the global segregation index SI for a community micrograph as the arithmetic mean of local segregation indices for each of $M$ focal pixels:

$$
S I(h)=\frac{1}{M} \sum_{i=1}^{M} s_{i}(h)
$$

$\operatorname{SI}(h)$ varies in value from 0.5 (high genetic mixing on spatial scale $h$ ) to 1.0 (no genetic mixing).

To assess printing fidelity, we generated reference images representing the idealised community structure (Supplementary Fig. 2e) and compared the resulting 
SI $(h)$ values with those measured for printed communities (Fig. 1h). This comparison revealed a good fit between measured and reference $S I(h)$ values for a range of spatial scales (Fig. $1 \mathrm{~h} ; h=5,10,20,50,100 \mathrm{px}$, equivalent to $7.6,15.2$, $30.3,75.8,151.5 \mu \mathrm{m})$, confirming that community printing is capable of modulating genetic mixing. Image processing and SI calculations were carried out using MATLAB ${ }^{\oplus}$ (MathWork $^{\oplus}$ ) (R2017a) and code is available at https://zenodo. org/record/4354822\#.X9zArJP7RPU.

Definitions and calculations. The term 'frequency' $(f)$ of a genotype, $a$, in a printed array containing genotype $a$ and $b$ after $18 \mathrm{~h}$ of competition is defined as

$$
f=\frac{A_{a}}{\left(A_{a}+A_{b}\right)}
$$

$A$ is the total cross-sectional area that a genotype occupies in the printed array. $A$ is calculated by segmentation of $z$-projected (by average intensity) confocal microscopy images of the printed array. $f$ is used in Figs. 1, 2, and 3. In Supplementary Fig. $2 \mathrm{a}, \mathrm{A}=$ total volume occupied by a strain, number of cells and number of CFUs for 3D segmentation, flow cytometry and CFU, respectively.

The term 'productivity' $(p)$ of a genotype, $a$, in a printed array after $18 \mathrm{~h}$ of competition is defined as

$$
p=\frac{A_{a}}{A_{S}}
$$

$A_{s}$ is the total cross-sectional area that a susceptible genotype occupies after $18 \mathrm{~h}$ of competition (at the same starting density and spatial pattern as genotype $a$ ), but without interference competition. For competition between two genotypes (Fig. 3), this would be the total cross-sectional area occupied by a susceptible strain at the given SI, competing against another susceptible strain. For competition between three genotypes (Fig. 4), this would be the total cross-sectional area occupied by a susceptible genotype in the strip (Fig. 4c), competing against the other two susceptible genotypes in the other strips.

\section{Data availability}

Raw datasets, including image-processing data and micrographs, generated and/or analysed during this study, are available in the figshare repository https://doi.org/ $10.6084 / \mathrm{m} 9$.figshare.1337957979. Source data are provided with this paper.

\section{Code availability}

Code used for 3D segmentation and subsequent analysis of z-projected and z-stacked confocal images is available at https://doi.org/10.5281/zenodo.4153224. The FAST tracking package, along with instructions on its use, is available at https://mackdurham. group.shef.ac.uk/FAST_DokuWiki/dokuwiki. Our written code for calculations of segregation indices is available at https://doi.org/10.5281/zenodo.4354822. The CRUK PlateLayout tool used to randomise cultures in 96-well plates is available at https:// github.com/crukci-bioinformatics/PlateLayout. Doubling times and lag phases were analysed from liquid culture growth curves using a custom-written script (https://doi. org/10.5281/zenodo.4328623) and DMFit 3.5 (https://www.combase.cc/index.php/en/8 category-en-gb/21-tools), respectively.

Received: 4 November 2020; Accepted: 6 January 2021; Published online: 08 February 2021

\section{References}

1. West, S. A., Diggle, S. P., Buckling, A., Gardner, A. \& Griffin, A. S. The social lives of microbes. Annu. Rev. Ecol. Evol. Syst. 38, 53-77 (2007).

2. Little, A. E. F., Robinson, C. J., Peterson, S. B., Raffa, K. F. \& Handelsman, J. Rules of engagement: interspecies interactions that regulate microbial communities. Annu. Rev. Microbiol. 62, 375-401 (2008).

3. Waters, C. M. \& Bassler, B. L. Quorum sensing: cell-to-cell communication in bacteria. Annu. Rev. Cell Dev. Biol. 21, 319-346 (2005).

4. Hibbing, M. E., Fuqua, C., Parsek, M. R. \& Peterson, S. B. Bacterial competition: surviving and thriving in the microbial jungle. Nat. Rev. Microbiol. 8, 15-25 (2009).

5. Nadell, C. D., Drescher, K. \& Foster, K. R. Spatial structure, cooperation and competition in biofilms. Nat. Rev. Microbiol. 14, 589-600 (2016).

6. Donaldson, G. P., Lee, S. M. \& Mazmanian, S. K. Gut biogeography of the bacterial microbiota. Nat. Rev. Microbiol. 14, 20-32 (2016).

7. Stacy, A., McNally, L., Darch, S. E., Brown, S. P. \& Whiteley, M. The biogeography of polymicrobial infection. Nat. Rev. Microbiol. 14, 93-105 (2016).

8. Mark Welch, J. L., Rossetti, B. J., Rieken, C. W., Dewhirst, F. E. \& Borisy, G. G. Biogeography of a human oral microbiome at the micron scale. Proc. Natl Acad. Sci. USA 113, 791-800 (2016).

9. Wilbert, S. A., Mark Welch, J. L. \& Borisy, G. G. Spatial ecology of the human tongue dorsum microbiome. Cell. Rep. 30, 4003-4015.e3 (2020).
10. Tropini, C., Earle, K. A., Huang, K. C. \& Sonnenburg, J. L. The gut microbiome: connecting spatial organization to function. Cell Host Microbe 21, 433-442 (2017).

11. Cordero, O. X. \& Datta, M. S. Microbial interactions and community assembly at microscales. Curr. Opin. Microbiol. 31, 227-234 (2016).

12. Kreft, J. U. Biofilms promote altruism. Microbiology 150, 2751-2760 (2004).

13. Xavier, J. B. \& Foster, K. R. Cooperation and conflict in microbial biofilms. Proc. Natl Acad. Sci. USA 104, 876-881 (2007).

14. Nadell, C. D., Xavier, J. B., Levin, S. A. \& Foster, K. R. The evolution of quorum sensing in bacterial biofilms. PLoS Biol. 6, e14 (2008).

15. Nadell, C. D. et al. Cutting through the complexity of cell collectives. Proc. $R$. Soc. Lond., B, Biol. Sci. 280, 20122770 (2013).

16. Nadell, C. D., Foster, K. R. \& Xavier, J. B. Emergence of spatial structure in cell groups and the evolution of cooperation. PLoS Comput. Biol. 6, e1000716 (2010)

17. Borenstein, D. B., Meir, Y., Shaevitz, J. W. \& Wingreen, N. S. Non-local interaction via diffusible resource prevents coexistence of cooperators and cheaters in a lattice model. PLoS ONE 8, e63304 (2013).

18. Mitri, S., Xavier, J. B. \& Foster, K. R. Social evolution in multispecies biofilms Proc. Natl Acad. Sci. USA 108, 10839-10846 (2011).

19. Estrela, S. \& Brown, S. P. Metabolic and demographic feedbacks shape the emergent spatial structure and function of microbial communities. PLoS Comput. Biol. 9, e1003398 (2013).

20. Momeni, B., Brileya, K. A., Fields, M. W. \& Shou, W. Strong inter-population cooperation leads to partner intermixing in microbial communities. eLife 2, e00230 (2013).

21. Momeni, B., Waite, A. J. \& Shou, W. Spatial self-organization favors heterotypic cooperation over cheating. eLife 2, e00960 (2013).

22. Chao, L. \& Levin, B. R. Structured habitats and the evolution of anticompetitor toxins in bacteria. Proc. Natl Acad. Sci. USA 78, 6324-6328 (1981).

23. Kerr, B., Riley, M. A., Feldman, M. W. \& Bohannan, B. J. M. Local dispersal promotes biodiversity in a real-life game of rock-paper-scissors. Nature 418, 171-174 (2002)

24. Majeed, H., Gillor, O., Kerr, B. \& Riley, M. A. Competitive interactions in Escherichia coli populations: the role of bacteriocins. ISME J. 5, 71-81 (2011).

25. Pande, S. et al. Privatization of cooperative benefits stabilizes mutualistic cross-feeding interactions in spatially structured environments. ISME J. 10, 1413-1423 (2016)

26. Gonzalez, D., Sabnis, A., Foster, K. R. \& Mavridou, D. A. I. Costs and benefits of provocation in bacterial warfare. Proc. Natl Acad. Sci. USA 115, 7593-7598 (2018).

27. Kim, W., Racimo, F., Schluter, J., Levy, S. B. \& Foster, K. R. Importance of positioning for microbial evolution. Proc. Natl Acad. Sci. USA 111, 1639-1647 (2014).

28. Walker, A. W. et al. The species composition of the human intestinal microbiota differs between particle-associated and liquid phase communities. Environ. Microbiol. 10, 3275-3283 (2008).

29. Mark Welch, J. L., Hasegawa, Y., McNulty, N. P., Gordon, J. I. \& Borisy, G. G. Spatial organization of a model 15-member human gut microbiota established in gnotobiotic mice. Proc. Natl Acad. Sci. USA 114, E9105-E9114 (2017).

30. Kim, D. et al. Spatial mapping of polymicrobial communities reveals a precise biogeography associated with human dental caries. Proc. Natl Acad. Sci. USA 117, 12375-12386 (2020).

31. Kim, H. J., Boedicker, J. Q., Choi, J. W. \& Ismagilov, R. F. Defined spatial structure stabilizes a synthetic multispecies bacterial community. Proc. Natl Acad. Sci. USA 105, 18188-18193 (2008).

32. Dal Co, A., van Vliet, S. \& Ackermann, M. Emergent microscale gradients give rise to metabolic cross-feeding and antibiotic tolerance in clonal bacterial populations. Philos. Trans. R. Soc. B 374, 20190080 (2019).

33. Dal Co, A., van Vliet, S., Kiviet, D. J., Schlegel, S. \& Ackermann, M. Shortrange interactions govern the dynamics and functions of microbial communities. Nat. Ecol. Evol. 4, 366-375 (2020).

34. Merrin, J., Leibler, S. \& Chuang, J. S. Printing multistrain bacterial patterns with a piezoelectric inkjet printer. PLoS ONE 2, e663-e667 (2007).

35. Connell, J. L., Ritschdorff, E. T., Whiteley, M. \& Shear, J. B. 3D printing of microscopic bacterial communities. Proc. Natl Acad. Sci. USA 110, 18380-18385 (2013)

36. Lehner, B. A. E., Schmieden, D. T. \& Meyer, A. S. A straightforward approach for 3D bacterial printing. ACS Synth. Biol. 6, 1124-1130 (2017).

37. Liu, X. et al. $3 \mathrm{D}$ printing of living responsive materials and devices. $A d v$. Mater. 30, 1704821 (2017).

38. Schaffner, M., Rühs, P. A., Coulter, F., Kilcher, S. \& Studart, A. R. 3D printing of bacteria into functional complex materials. Sci. Adv. 3, eaao6804 (2017).

39. Gupta, S. et al. Investigating the dynamics of microbial consortia in spatially structured environments. Nat. Commun. 11, 2418 (2020).

40. Holden, M. A., Needham, D. \& Bayley, H. Functional bionetworks from nanoliter water droplets. J. Am. Chem. Soc. 129, 8650-8655 (2007).

41. Villar, G., Graham, A. D. \& Bayley, H. A tissue-like printed material. Science 340, 48-52 (2013). 
42. Gordon, D. M., Riley, M. A. \& Pinou, T. Temporal changes in the frequency of colicinogeny in Escherichia coli from house mice. Microbiology 144, 2233-2240 (1998).

43. Riley, M. A. \& Gordon, D. M. The ecological role of bacteriocins in bacterial competition. Trends Microbiol. 7, 129-133 (1999).

44. Riley, M. A. \& Chavan, M. A. Bacteriocins (Springer Berlin Heidelberg, 2007).

45. Granato, E. T. \& Foster, K. R. The evolution of mass cell suicide in bacterial warfare. Curr. Biol. 30, 2836-2843 (2020).

46. Gardner, A. \& West, S. A. Spite and the scale of competition. J. Evolution Biol. 17, 1195-1203 (2004).

47. Gardner, A., West, S. A. \& Buckling, A. Bacteriocins, spite and virulence. Proc. R. Soc. Lond., B, Biol. Sci. 271, 1529-1535 (2004).

48. Bucci, V., Nadell, C. D. \& Xavier, J. B. The evolution of bacteriocin production in bacterial biofilms. Am. Nat. 178, E162-E173 (2011).

49. Mavridou, D. A. I., Gonzalez, D., Kim, W., West, S. A. \& Foster, K. R. Bacteria use collective behavior to generate diverse combat strategies. Curr. Biol. 28, 345-355 (2018).

50. Timmis, K. \& Hedges, A. J. The killing of sensitive cells by colicin D. Biochim. Biophys. Acta 262, 200-207 (1972).

51. Shannon, R. \& Hedges, A. J. Kinetics of lethal adsorption of colicin E2 by Escherichia coli. J. Bacteriol. 93, 1353-1359 (1967).

52. Ghazaryan, L., Giladi, I. \& Gillor, O. The effects of colicin production rates on allelopathic interactions in Escherichia coli populations. Microorganisms 7, 564 (2019).

53. Berryman, A. A. \& Hawkins, B. A. The refuge as an integrating concept in ecology and evolution. Oikos 115, 192-196 (2006).

54. Durrett, R. \& Levin, S. Allelopathy in spatially distributed populations. J. Theor. Biol. 185, 165-171 (1997).

55. Coyte, K. Z., Schluter, J. \& Foster, K. R. The ecology of the microbiome: networks, competition, and stability. Science 350, 663-666 (2015).

56. Pugsley, A. P. Autoinduced synthesis of colicin E2. Mol. Gen. Genet. 190, 379-383 (1983).

57. Ghazaryan, L., Soares, M. I. M. \& Gillor, O. Auto-regulation of DNA degrading bacteriocins: molecular and ecological aspects. Antonie van. Leeuwenhoek 105, 823-834 (2014).

58. Cascales, E. et al. Colicin biology. Microbiol. Mol. Biol. R. 71, 158-229 (2007).

59. Inglis, R. F., Hall, A. R. \& Buckling, A. The role of 'soaking' in spiteful toxin production in Pseudomonas aeruginosa. Biol. Lett. 9, 20120569 (2012).

60. Rendueles, O., Amherd, M. \& Velicer, G. J. Positively frequency-dependent interference competition maintains diversity and pervades a natural population of cooperative microbes. Curr. Biol. 25, 1673-1681 (2015).

61. Xu, K. D., Stewart, P. S., Xia, F., Huang, C. T. \& McFeters, G. A. Spatial physiological heterogeneity in Pseudomonas aeruginosa biofilm is determined by oxygen availability. Appl. Environ. Microbiol. 64, 4035-4039 (1998).

62. Walters, M. C., Roe, F., Bugnicourt, A., Franklin, M. J. \& Stewart, P. S Contributions of Antibiotic penetration, oxygen limitation, and low metabolic activity to tolerance of Pseudomonas aeruginosa biofilms to ciprofloxacin and tobramycin. Antimicrob. Agents Chemother. 47, 317-323 (2003).

63. Stewart, P. S. \& Franklin, M. J. Physiological heterogeneity in biofilms. Nat. Rev. Micro 6, 199-210 (2008).

64. Nadell, C. D., Xavier, J. B. \& Foster, K. R. The sociobiology of biofilms. FEMS Microbiol. Rev. 33, 206-224 (2009).

65. Alcinesio, A. et al. Controlled packing and single-droplet resolution of 3Dprinted functional synthetic tissues. Nat. Commun. 11, 2105 (2020).

66. $\mathrm{Li}, \mathrm{W}$. et al. Dual recognition and the role of specificity-determining residues in colicin E9 DNase-immunity protein interactions. Biochemistry 37, 11771-11779 (1998).

67. Ghazaryan, L., Tonoyan, L., Ashhab, A. A., Soares, M. I. M. \& Gillor, O. The role of stress in colicin regulation. Arch. Microbiol. 196, 753-764 (2014).

68. Cianfanelli, F. R., Cunrath, O. \& Bumann, D. Efficient dual-negative selection for bacterial genome editing. BMC Microbiol. 20, 129 (2020).

69. Hecht, A., Endy, D., Salit, M. \& Munson, M. S. When wavelengths collide: bias in cell abundance measurements due to expressed fluorescent proteins. ACS Synth. Biol. 5, 1024-1027 (2016).

70. Baranyi, J. \& Roberts, T. A. A dynamic approach to predicting bacterial growth in food. Int. J. Food Microbiol. 23, 277-294 (1994).

71. White, P. et al. Exploitation of an iron transporter for bacterial protein antibiotic import. Proc. Natl Acad. Sci. USA 114, 12051-12056 (2017).

72. Schindelin, J. et al. Fiji: an open-source platform for biological-image analysis. Nat. Methods 9, 676-682 (2012).

73. Lindeberg, T. Edge detection and ridge detection with automatic scale selection. Int. J. Comput. Vis. 30, 117-156 (1998).

74. Meyer, F. Topographic distance and watershed lines. Signal Process. 38 113-125 (1994).
75. Berg, de, M, Kreveld, van, M, Overmars, M. \& Schwarzkopf, O. Computational Geometry. Ch. 9 (Springer, Berlin, Heidelberg, 1997).

76. Sato, Y. et al. Three-dimensional multi-scale line filter for segmentation and visualization of curvilinear structures in medical images. Med. Image Anal. 2, 143-168 (1998)

77. Jin, J., Yang, L., Zhang, X. \& Ding, M. Vascular tree segmentation in medical images using Hessian-based multiscale filtering and level set method. Comput. Math Methods Med. 2013, 502013 (2013).

78. Otsu, N. A threshold selection method from gray-level histograms. IEEE T. Syst. Man. Cy-S 9, 62-66 (1979).

79. Krishna Kumar, R. et al. Image processing data, micrographs, and confocal microscopy images of printed arrays containing E. coli. Figshare, https://doi. org/10.6084/m9.figshare.13379579 (2020).

\section{Acknowledgements}

This research was supported by a European Research Council Advanced Grant SYNTISU, which supports R.K.K., L.Z., G.S.P. and H.B., and by a European Research Council Advanced Grant 787932 and a Wellcome Trust Investigator award 209397/Z/17/Z to K.R.F. and W.P.J.S. T.A.M.-L. and A.A. acknowledge funding from the University of Oxford, and the EPSRC \& BBSRC Centre for Doctoral Training in Synthetic Biology (grant EP/L016494/1), and A.A. also acknowledges funding from a Clarendon Fund Scholarship. O.J.M. acknowledges funding from the EPSRC Life Sciences Interface Centre for Doctoral Training (grant EP/F500394/1). D.G. acknowledges funding from the Swiss National Science Foundation Postdoc Mobility Fellowships P2LAP3_155109 and P300PA 167703. D.A.I.M. acknowledges funding from the MRC Career Development Award MR/M009505/1. The authors thank the electronic and mechanical workshops in the Physical and Theoretical Chemistry Department for aid in the design and construction of the piezo drivers, Olivier Cunrath, Nicholas Housden and Colin Kleanthous for plasmids, Connor Sharp and Daniel Unterweger for useful discussions and Elisa Granato for spotting and imaging colonies for Fig. $1 \mathrm{~b}$.

\section{Author contributions}

R.K.K., D.G., W.K., G.S.P., H.B. and K.R.F. conceived and designed experiments. R.K.K. and K.R.F. wrote the paper, with comments from other authors. R.K.K., T.A.M.-L. and A.A. performed experiments. O.J.M. and W.P.J.S. wrote custom software for image analysis of printed arrays and calculation of segregation indices, respectively. D.A.I.M. and D.G. designed and generated the colicin toolbox. L.Z. designed and built the highpower piezo driver.

\section{Competing interests}

The authors declare no competing interests.

\section{Additional information}

Supplementary information The online version contains supplementary material available at https://doi.org/10.1038/s41467-021-20996-w.

Correspondence and requests for materials should be addressed to H.B. or K.R.F.

Peer review information Nature Communications thanks the anonymous reviewer(s) for their contribution to the peer review of this work.

Reprints and permission information is available at http://www.nature.com/reprints

Publisher's note Springer Nature remains neutral with regard to jurisdictional claims in published maps and institutional affiliations.

Open Access This article is licensed under a Creative Commons Attribution 4.0 International License, which permits use, sharing, adaptation, distribution and reproduction in any medium or format, as long as you give appropriate credit to the original author(s) and the source, provide a link to the Creative Commons license, and indicate if changes were made. The images or other third party material in this article are included in the article's Creative Commons license, unless indicated otherwise in a credit line to the material. If material is not included in the article's Creative Commons license and your intended use is not permitted by statutory regulation or exceeds the permitted use, you will need to obtain permission directly from the copyright holder. To view a copy of this license, visit http://creativecommons.org/ licenses/by/4.0/.

(C) The Author(s) 2021 